\title{
PLANT DisEASES RECOGNITION ON IMAGES USING Convolutional Neural Networks: A SystematiC REVIEW
}

A PREPRINT

André S. Abade, Paulo Afonso Ferreira and Flávio de Barros Vidal

September 10, 2020

\begin{abstract}
Plant diseases are considered one of the main factors influencing food production and minimize losses in production, and it is essential that crop diseases have fast detection and recognition. The recent expansion of deep learning methods has found its application in plant disease detection, offering a robust tool with highly accurate results. In this context, this work presents a systematic review of the literature that aims to identify the state of the art of the use of convolutional neural networks(CNN) in the process of identification and classification of plant diseases, delimiting trends, and indicating gaps. In this sense, we present 121 papers selected in the last ten years with different approaches to treat aspects related to disease detection, characteristics of the data set, the crops and pathogens investigated. From the results of the systematic review, it is possible to understand the innovative trends regarding the use of CNNs in the identification of plant diseases and to identify the gaps that need the attention of the research community.
\end{abstract}

\section{Introduction}

Plant diseases are considered one of the main factors influencing food production, being responsible for the significant reduction of the physical or economic productivity of the crops and, in some instances, maybe an impediment to this activity. According to [1], to minimize production losses and maintain crop sustainability, it is essential that disease management and control measures be carried out appropriately, highlighting the constant monitoring of the crop, combined with the rapid and accurate diagnosis of the diseases. These practices are the most recommended by phytopathologists [1].

The major challenge for agriculture is the correct identification of the symptoms of major diseases that affect crops [2]. Manual and mechanized practices in traditional planting processes are not able to cover large areas of plantation and provide essential early information to decision-making processes, according to [3]. Thus, it is necessary to develop auTomatod solutions, practical, reliable, and economically able to monitor the health of plants providing meaningful information to the decision-making process, for example, the application and correct dosage of pesticides in specific treatment certain diseases [4].

Computer Vision, along with Artificial Intelligence (AI), has been developing techniques and methods for recognizing and classifying objects with significant advances [5]. These systems use Convolutional Neural Networks (CNNs) [6], and their results in some experiments are already superior to humans in large-scale reconnaissance tasks. The works of [7] and [8] highlight the use of images as one of the most advanced methods of detection and recognition of plant diseases.

Many approaches already make use of popular architectures such as LeNet[9], AlexNet[10], VGGNet[11], GoogLeNet[12], InceptionV3[13], ResNet[14] and DenseNet[15], considerably increasing the accuracy in the identification of plant diseases. However, numerous challenges still hinder the correct classification of phytopathology, such as the genetic and phenotypic diversity of crops, the wide variety of pests and diseases. As well as the characteristics of the data sets, the types, and peculiarities of network architectures and models convolutional neural and the complexity involved in the results optimization techniques. 
Thus, this systematic literature review (SLR) is intended to characterize the state of the art recognition and identification of plant diseases using convolutional neural networks. The investigation sought significant contributions regarding the challenges listed and the different innovations that aim to improve the performance of CNNs and, consequently the correct identification of diseases. A systematic literature review is a type of scientific research that aims to present an unbiased report about a research topic, following a methodology that is reliable, accurate and that allows auditing [16, 17].

The remainder of the paper is organized as follows: In Section 2 presented the background. Section 3 describes our review protocol in detail. Section 4 presents the results of the SLR. Section 5 presents the discussion and finally Section 6 concludes the paper.

\section{Background}

The identification of plant diseases is one of the most basic and essential agricultural activities. In most cases, identification is performed manually, visually, by serological and molecular tests or by microscopy. The problem with the visual assessment to identify diseases is that the evaluating subject has assumed a subjective task, prone to psychological and cognitive phenomena that can lead to prejudice, optical illusions, and, finally, error[18].

\subsection{Types of Plant Diseases}

Plant diseases are classified according to the type of their causative agent. Diseases originating from living organisms are called biotic, unlike diseases that are produced by non-living ecological circumstances, called abiotic[19]. Fungi, bacteria, viruses, plague, nematodes are the leading causes of different forms of biotic diseases[20]. In this study, the pest or plague, or more specifically, biological pest, is the outbreak of certain species harmful to agricultural development that cause epidemic diseases in plants and their cultivars.

\subsection{Plant Disease Detection System}

The automated solutions for the identification of plant diseases using images and machine learning, especially CNNs, have provided significant advances to maximize the accuracy of correct diagnosis. Convolutional Neural Networks is a subset of machine learning approaches that have emerged as a versatile tool for assimilating large amounts of heterogeneous data and providing reliable predictions of complex and uncertain phenomena[21].

\subsection{Evolution of CNN architectures}

Different innovations in CNN architectures have been proposed since 1998 with the presentation of LeNet-5[9]. It can be categorized as parameter optimization, regularization, structural reformulation, etc. However, it is observed that the main improvement in the performance of CNNs is motivated by the fundamental reformulation and design of new blocks[22]. Thus, this SLR classifies as new architecture that is by the innovation proposals reported in studies of [22] and [21].

\subsection{Transfer Learning}

Transfer learning is a method that reuses models applied to specific tasks as a starting point for a model related to a new domain of interest. Thus, the objective is to borrow labeled or extract knowledge from some related fields to obtain the highest possible performance in the area of interest[23, 24].

As per standard practices, there are two ways to approach transfer learning [25]:

- Using the base neural network as a fixed feature extractor: In this case, the images of the target dataset are fed to the neural network, and the features that generate as input to the final classifier layer are extracted. Through these features, a new classifier is built, and the model is created.

- Fine Tuning the base network: In this case, the final classifier layer is replaced, just like the above case but using backpropagation algorithms, the weights of previous layers are also modified.

\subsection{Custom Layers}

Traditional CNN Architectures build their models using three types of layers, namely Input, Intermediate, and Output[22]. Generally, Frameworks have a list of standardized layers according to the most relevant models that already exist. 
However, when the peculiarities of the problem demand a need to operate at a lower level of abstraction, the need arises to implement a customized or personalized layer that meets the specific demand. For example, when using ResNet for a particular purpose, there is a need to add an extra layer to the end of the model that normalizes the classifier output.

In this way, Custom Layers are defined as those that are not included in a list of known layers and implemented natively by the Frameworks, through the most relevant models. It should be noted that the implementation of customized layers based on an existing architecture or model, does not constitute a new architecture or model[26].

\subsection{Data Augmentation}

One of the successful approaches that seek to mitigate the problem of the ability to generalize models is data augmentation. In this approach, the original data set is augmented by several techniques seeking a more comprehensive representation possible of the problem domain, minimizing the distance between the training and validation set [27].

The data augmentation uses the methods of (Data Warping) or super-sampling (Oversampling), that artificially increase the size of the training data set. Data distortion transforms existing images so that their label is preserved, using techniques such as geometric transformations, color space, image slices, rotation, translation, adding noise, kernel filters.

\section{Planning Review}

The planning of this SLR followed the processes defined by [17]. To provide transparency and allow the replication and auditing of the entire process (essential requirements in systematic reviews), the StArt Tool (State of the Art Through Systematic Review) was used [28], which supports all phases of an SLR.

In the planning phase, we need to identify the real need, namely the motivation for implementing the SLR. Thus, defining the objectives and elaborating a protocol for SLR are essential elements for successful execution of the technique. It should be noted that the quality of the protocol directly impacts the SLR results.

\subsection{Research Questions}

It is known that CNNs have been showing better results than traditional Computer Vision techniques and other techniques using Machine Learning. Thus, this RSL is intended to identify the characteristics that affect the efficiency of plant disease identification approaches using convolutional neural networks. And the main research question of SRL that we intend to answer is:

"How are convolutional neural networks innovating and overcoming the challenges of the plant disease identification process?"

Additionally, secondary questions were formulated to assist in the identification of characteristics that determine the desired response, namely:

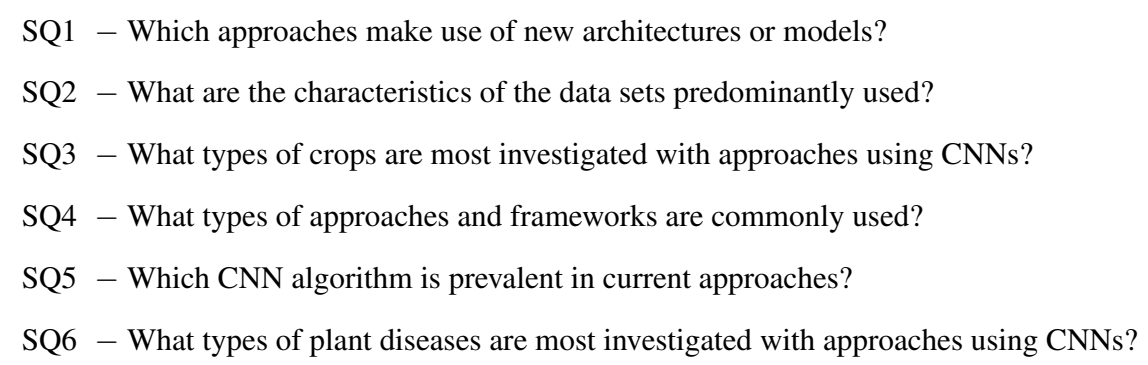

\subsection{Search Strategy}

This SLR focuses its research on digital scientific databases, so any type of gray literature was not included in the investigation process. The study is based on the assumption that most of the research with relevant results that may appear in the gray literature are typically described or referenced in scientific papers already published. 
The search and selection strategy for primary studies focused on 5 indexed electronic databases, namely: ACM Library 1 IEEE Xplore Digital Libray ${ }^{2}$, Elsevier Scopus ${ }^{3}$ Springer Link ${ }^{4}$ and Google Academic 5 The databases were selected because they offer the largest volume of high-impact scientific conference proceedings and journals, broadly covering the field of investigations on plant diseases and machine learning through CNNs.

According to [29] and [17], the process of collecting the study set begins, by defining the Search String. Thus, the Search String should be formulated based on the experience of the researchers and reviewers involved in the SLR process. Even though different indexed research repositories define their syntax for building search strings, we initially defined the following generic string that was later customized for each search engine:

$$
\begin{gathered}
\text { ("plant disease" OR "plant pathology" OR "crop disease") } \\
\text { AND } \\
\text { ("machine learning" OR "convolutional neural network" OR "deep learning" OR "DNN" OR "CNN") }
\end{gathered}
$$

\subsection{Study Selection Criteria}

The identification and recognition of plant diseases through convolutional neural networks has aroused a high interest in the scientific community in the last decade. Therefore, publications from the previous ten years (from 2010 to 2019) were selected.

The search string had a broad scope intentionally because we did not want to miss any potentially exciting research. This full scope has led to a large number of papers, from which we filtered the most relevant ones using the selection criteria presented in Table 1 .

Table 1: Selection criteria for studies defined in the SLR planning protocol

\begin{tabular}{lccll}
\hline \multirow{2}{*}{ ID } & \multicolumn{3}{c}{ Creterion Type } & \\
\cline { 2 - 3 } & Inclusion & Exclusion & & \multicolumn{1}{c}{ Description } \\
\hline C1 & $\mathrm{X}$ & - & Studies that approaches the identification of plant diseases through convolutional neural networks. \\
C2 & $\mathrm{X}$ & - & Studies that present new models or architectures of convolutional networks. \\
C3 & $\mathrm{X}$ & - & Studies describing techniques or methods for identifying plant diseases using CNNs. \\
C4 & - & $\mathrm{X}$ & Studies without full text available \\
C5 & - & $\mathrm{X}$ & Studies not written in English \\
C6 & - & $\mathrm{X}$ & Duplicate publication from multiple sources \\
C7 & - & $\mathrm{X}$ & Studies without qualifying data for extraction \\
C8 & - & $\mathrm{X}$ & Studies that do not use CNNs as the main approach \\
\hline
\end{tabular}

Once identified, studies need to be selected through the application of selection criteria (which are the inclusion and exclusion criteria) and can be evaluated by the quality criteria. The selection criteria must specify the main characteristics and/or content that the studies must have to be included or excluded.

\subsection{Study Quality Assessment}

The quality criteria aim to evaluate methodological aspects of the studies, that is, they can be considered issues such as the relevance of the research theme and the use of methods that lead to the objectives proposed in the study.

The quality assessment is performed using forms developed by the researchers. These are composed of quality criteria, that is, questions about methodological aspects of each study[30, 31]. Table 2 presents the items that make up the study quality assessment form.

We chose the criteria based on their influence on the quality of the final product. Points were given to each of the five criteria based on the following scale: yes $=1$, partially $=0.5$, not $=0$.

The quality of each study is directly associated with its methodological quality, which can be measured by aspects such as internal validity (effectively measuring what you want to measure), external validity (ability to generalize the results), the relevance of the research topic (questions research and well-defined objectives and based on the literature), adoption of methods that lead to the proposed goals, among others.

\footnotetext{
${ }^{1}$ https://dl.acm.org access:January/2020

${ }^{2}$ https://ieeexplore.ieee.org/Xplore access:January/2020

${ }^{3} \mathrm{https}: / /$ www.scopus.com access:January/2020

${ }^{4}$ https://link.springer.com access:January/2020

${ }^{5}$ https://www.scholar.google.com access:January/2020
} 
Table 2: Criteria for Quality Assessment of studies defined in the SLR planning protocol.

\begin{tabular}{|c|c|c|c|c|c|}
\hline ID & Question & \multicolumn{3}{|c|}{ Indicator } & \multirow{2}{*}{ Reference } \\
\hline \multirow{3}{*}{ Q1 } & \multirow{3}{*}{ Are the studies cited by other works and scientific investigations? } & & $\mathbf{P}$ & $\mathbf{N}$ & \\
\hline & & \multirow{2}{*}{1,0} & \multirow{2}{*}{0,5} & \multirow{2}{*}{0,0} & ith a significant number of citations. \\
\hline & & & & & $\begin{array}{l}\text { Partially } \Rightarrow \text { Studies published with a low } \mathrm{nt} \\
\text { Not } \Rightarrow \text { Studies published without citations }\end{array}$ \\
\hline \multirow{3}{*}{ Q2 } & \multirow{3}{*}{$\begin{array}{l}\text { Do the studies describe the approaches in detail and provide subsidies } \\
\text { for replication and finding results? }\end{array}$} & \multirow{3}{*}{1,0} & \multirow{3}{*}{0,5} & \multirow{3}{*}{0,0} & Yes $\Rightarrow$ Studies explicitly describe the approaches; \\
\hline & & & & & $\begin{array}{l}\text { Partially } \Rightarrow \text { Studies describe the approaches, however, they do not provide } \\
\text { subsidies for replication and verification of results }\end{array}$ \\
\hline & & & & & $\begin{array}{l}\text { Not } \Rightarrow \text { Studies that do not provide sufficient characteristics to describe } \\
\text { the approaches, nor do they allow replication and auditing; }\end{array}$ \\
\hline \multirow[b]{2}{*}{ Q3 } & \multirow{2}{*}{$\begin{array}{l}\text { Are the main findings stated clearly? regarding creditability, validity, and } \\
\text { reliability? }\end{array}$} & \multirow[b]{2}{*}{1,0} & \multirow[b]{2}{*}{0,5} & \multirow[b]{2}{*}{0,0} & Yes $\Rightarrow$ The findings are clearly reported \\
\hline & & & & & Partially $\Rightarrow$ The main findings are partially reliable and credible. \\
\hline \multirow{3}{*}{ Q4 } & \multirow{3}{*}{ Are the limitations of the studies clearly specified and documented? } & \multirow{3}{*}{1,0} & \multirow{3}{*}{0,5} & \multirow{3}{*}{0,0} & Yes $\Rightarrow$ Specifies and documents study limitations \\
\hline & & & & & $\begin{array}{l}\text { Partially } \Rightarrow \text { It mentions the limitations, however it does not specify } \\
\text { or document its determinants. }\end{array}$ \\
\hline & & & & & $\begin{array}{l}\text { Not } \Rightarrow \text { It does not mention the limitations and threats of validity } \\
\text { of the studies. }\end{array}$ \\
\hline \multirow{3}{*}{ Q5 } & \multirow{3}{*}{ Are the conclusions credible and consistent with the results presented? } & \multirow{3}{*}{1,0} & \multirow{3}{*}{0,5} & \multirow{3}{*}{0,0} & $\begin{array}{l}\text { Yes } \Rightarrow \text { Methodologically prepared studies with consistency of facts and } \\
\text { confidence in the discoveries presented }\end{array}$ \\
\hline & & & & & $\begin{array}{l}\text { Partially } \Rightarrow \text { Methodologically elaborated studies, but with insufficient } \\
\text { details to certify the results and conclusions. }\end{array}$ \\
\hline & & & & & Not $\Rightarrow$ Studies methodologically poorly elaborated and without credibility. \\
\hline
\end{tabular}

Primary studies that obtained a quality index (IQ) of less than 3 points were excluded from this SLR, to guarantee the high quality of the summarized final set.

\subsection{Data Extraction and Synthesis}

To elect the primary studies, we use the PRISMA (Preferred Reporting Items for Systematic and Meta-Analyses) recommendation, according to its four stages: identification, screening, extraction, and final selection[32]. In the identification, the study sample was extracted, quantified, and stored eliminating duplicate studies. In the screening stage, the reviews were pre-selected from reading the title, abstract, and keywords by two independent reviewers, obtaining a Kappa index $>80 \%(p<0.05)$ of interobserver agreement. Discrepancies were resolved by a third reviewer[33].

In the extraction stage, the full reading of pre-selected studies was performed, excluding studies that did not meet the inclusion criteria, defining the final sample. The synthesis activity aims to combine the data extracted from each of the selected primary studies, delineating the situation of the investigated research questions.

A total of 2,221 studies were retrieved, where 1,433 were identified in the Google Academic, 322 in the IEEE Library, 233 in the ACM Library database, 195 in the Elsevier Scopus, and 38 in the Springer Link.

During the identification phase, 91 duplicate studies were excluded, and during the initial selection, 682 reviews were eliminated because they did not meet the established inclusion criteria. For the extraction phase, 1,448 reviews were selected, and, after reading the entire text, 121 reviews were summarized. Figure 1 illustrates the steps followed in conducting the SLR with a summary of the results.

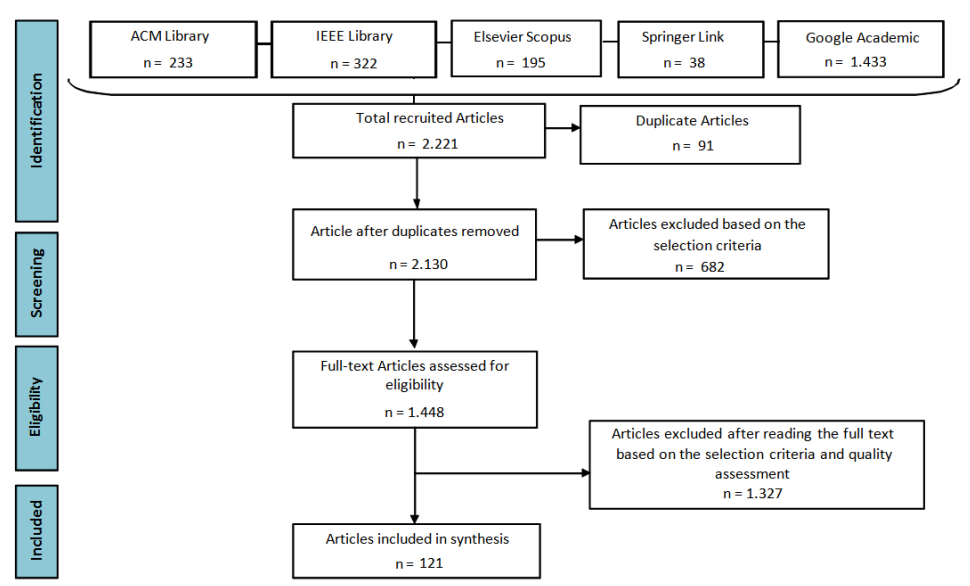

Figure 1: Flowchart of study phases and selections - adapted from [32] 
The investigation was carried out retrieving studies between the years 2010 to 2019, it is possible to note that the year 2012 is a milestone not only for studies that address convolutional networks, but also the application of this approach to the identification and recognition of plant diseases. Figure 2 presents the evolution of studies that address this theme.

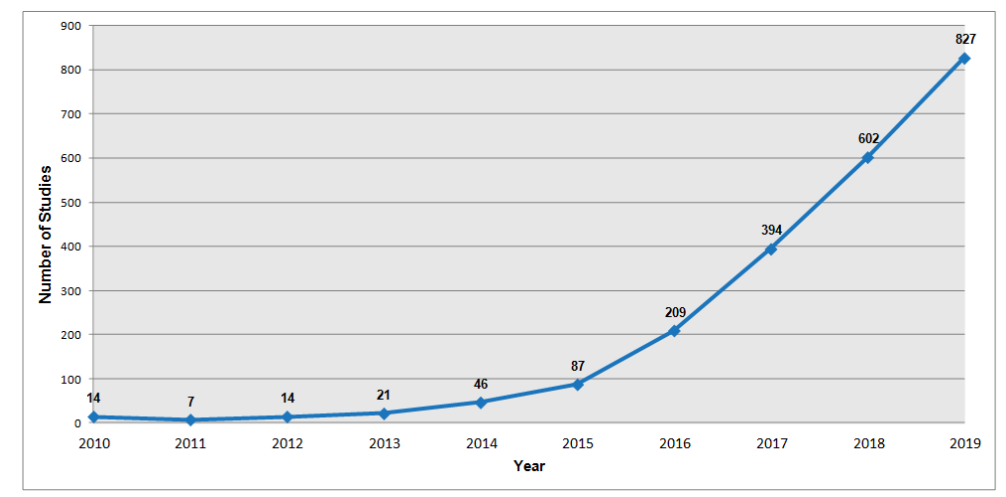

Figure 2: Temporal evolution of the quantity of publications recruited containing the keywords defined in the Search String in the last ten years (2010 to 2019)

Additionally, the studies identified were distributed geographically, as illustrated by Figure 3. It was noted that the investigations and consequently the scientific interest on the identification and recognition of plant diseases using machine learning techniques are coincident with the most populous countries in the world, among them: China, India, the United States of America, Indonesia, Pakistan, and Brazil.

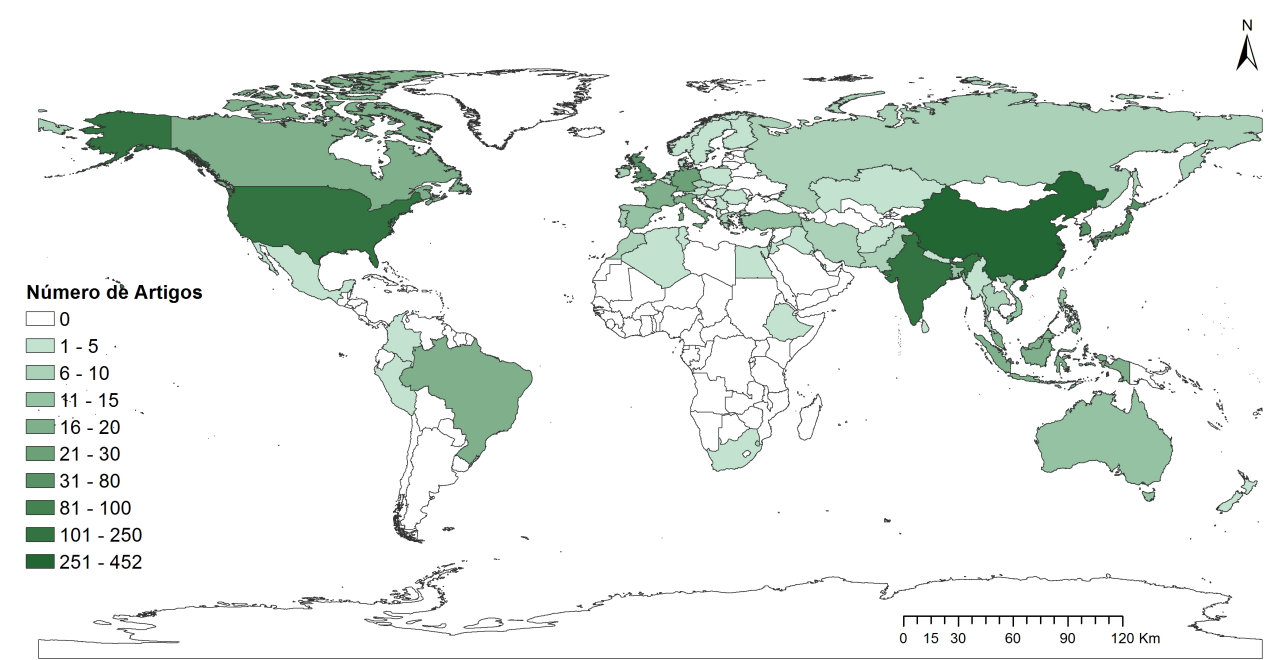

Figure 3: Geographical distribution of the studies identified in the SRL

At the end of the synthesis activities, Table 3 was prepared, available in Appendix A with 121 primary studies chosen for extraction. Basically, the table is composed by the following attributes: ID (Study identification), Refs (Author of the approach), IQ (Quality Index), Algorithm, Best accuracy, Dataset characteristics, Crop type, Image type, Language and Framework, Predominant approach. In addition, in Table 4, information about each investigated disease was detailed according to the type of crops and causative pathogen. Information from Table 4 is available in B

Each column of the Table summarizes a relevant feature of the investigation process that is directly related to the questions formulated for the SLR.

\section{Results}

In this section, we present the discrete and continuous quantitative data extracted from the 121 primary studies that support formulating the answers corresponding to the six secondary questions of the research. 


\subsection{SQ1: Which approaches make use of new architectures or models?}

To answer this question, the data extraction from the 121 summarized studies made it possible to group the investigations by practical approaches. Seven groups of methods were categorized, namely: Customizing Layers, Transfer Learning, New Architecture, Fine Tune and hyperparameters, Image Segmentation, Data Augmentation, and Unsupervised Learning.

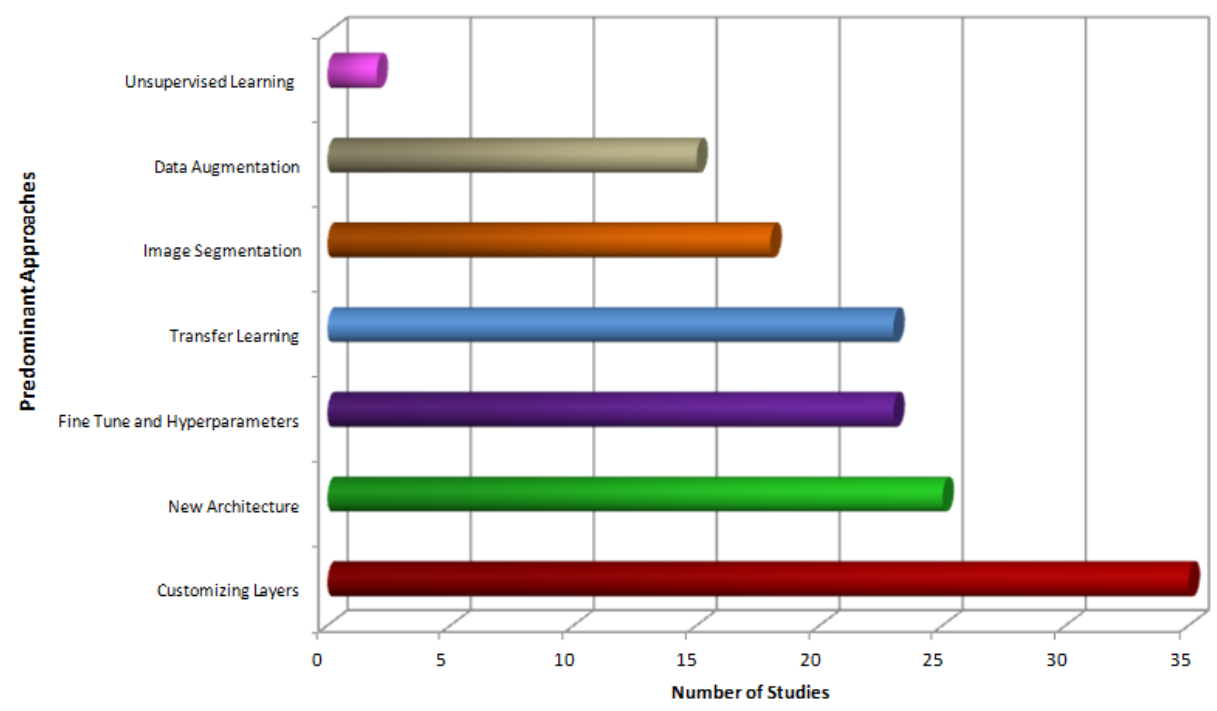

Figure 4: Predominant Approaches in 121 Summary Studies.

Among the 121 studies evaluated, it is possible to notice that only 25 studies (S1, S2, S6, S7, S11, S12, S13, S15, S22, S35, S43, S54, S61, S65, S68, S70, S75, S84, S86, S91, S100, S113, S114, S116, S120) propose a new architecture. In Figure 4, the distribution of studies by practical approaches is presented.

\subsection{SQ2: What are the characteristics of the data sets predominantly used?}

Regarding the predominance and characteristics of the data sets most used in the investigated studies, we highlight the customized initiatives designed mainly for a research need and the PlantVillage[34] data set. Figure 5] shows the distribution of studies by data set and type of image capture environment.

The customized Data Sets are present in 66 studies (S1, S2, S3, S6, S7, S8, S9, S12, S15, S17, S18, S20, S22, S24, S25, S28, S32, S33, S34, S36, S37, S38, S40, S43, S44, S45, S46, S47, S49, S50, S52, S58, S64, S68, S69, S70, S71, S73, S74, S75, S77, S79, S80, S82, S84, S87, S88, S89, S90, S91, S92, S95, S96, S97, S98, S100, S102, S103, S104, S107, S112, S113, S115, S116, S119, S121) and PlantVillage is used in your full or partial version in 45 studies (S3, S4, S9, S11, S13, S14, S18, S21, S23, S26, S27, S28, S29, S35, S41, S48, S51, S53, S55, S56, S57, S60, S61, S62, S63, S65, S66, S67, S68, S69, S72, S73, S76, S78, S81, S85, S86, S93, S99, S101, S105, S108, S110, S114, S117).

\subsection{SQ3: What types of crops are most investigated with approaches using CNNs?}

The types of crops present in the approaches that use CNNs to identify diseases are summarized graphically and presented in Figure 6 It is possible to observe that the type called "Diverse" categorizes all studies that use more than one type of crop in their approaches and consequently make use of a database with diversified plant phenotypes. In particular, this is a predominant feature in the PlantVillage data set.

Studies that investigate only one type of crop in particular highlight those that address the phytopathology of Tomato crop with 18 investigations (S3, S9, S27, S44, S48, S55, S58, S61, S67, S70, S75, S78, S86, S93, S99, S102, S105, S108). 


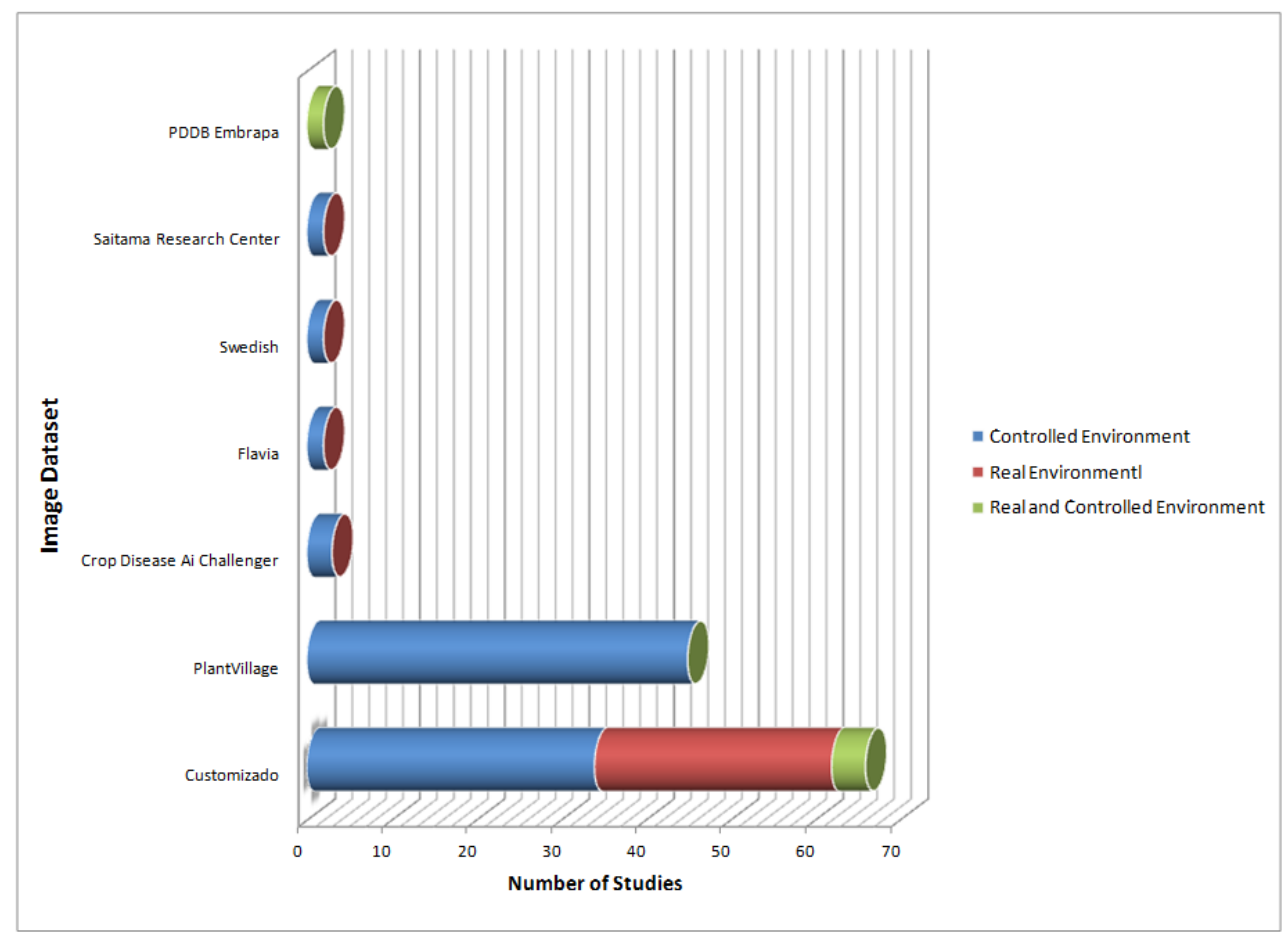

Figure 5: Characteristics of the Data Sets present in the 121 Summary Studies

\subsection{SQ4: What types of approaches and frameworks are commonly used?}

In the summary process, it was found that the investigated studies make use of 6 main FrameWorks, used to implement solutions involving machine learning, as well as predictive analysis. Figure 7 is apresented the distribution of studies grouped by the framework used in the approach development process.

TensorFlow is the most used framework in approaches that investigate plant diseases through convolutional neural networks. Among the 121 summarized studies, 38 investigations (S1, S2, S3, S5, S8, S11, S12, S14, S15, S23, S25, S27, S28, S38, S39, S40, S42, S44, S50, S53, S55 , S56, S61, S62, S63, S64, S65, S66, S68, S69, S70, S76, S77, S81, S86, S104, S106, S110) use the TensorFlow.

\subsection{SQ5: Which CNN algorithm is prevalent in current approaches?}

Deep learning is not a single approach, but a class of algorithms and topologies that can be applied to a wide variety of problems. In Figure 8, it is possible to follow the distribution of these algorithms grouped according to the 121 summarized studies.

Thirty algorithms used in the approaches were accounted for, with predominant algorithms that define the classic architectures, with emphasis on AlexNet and VGG. It should be noted that 19 studies (S1, S6, S7, S11, S12, S13, S22, S35, S43, S61, S68, S70, S75, S84, S86, S91, S100, S116, S120) propose new architectures and 15 (S9, S18, S19, S23, S32, S34, S39, S41, S42, S49, S50, S51, S53, S65, S103) investigations customize classic algorithms to solve the problem of identifying plant diseases using CNNs.

\subsection{SQ6: What types of plant diseases (biotic causative agents) are most investigated with approaches using CNNs?}

Using the data summarized in B we analyzed 54 datasets with 142 types of crops, associating each disease-causing pathogen to its large group, namely: Virus, Bacteria, Fungi, Algae, Plague, Nematodes and, Abiotics. In Figure 9, we present the type relationship of the crops with groups of pathogens, quantifying the number of occurrences of diseases investigated by their causative agents. 


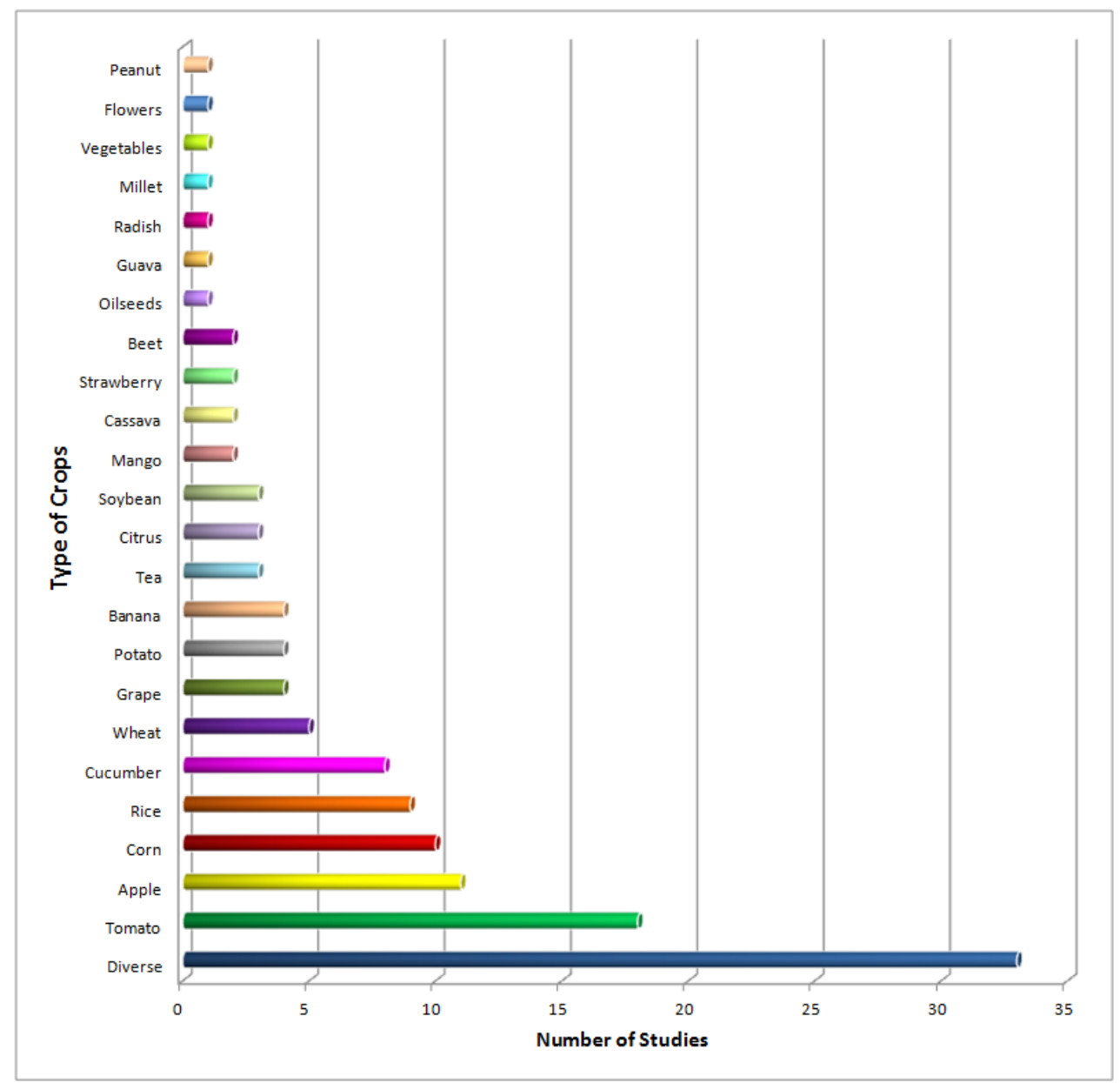

Figure 6: The most investigated crops in the 121 studies that apply CNNs to identify diseases

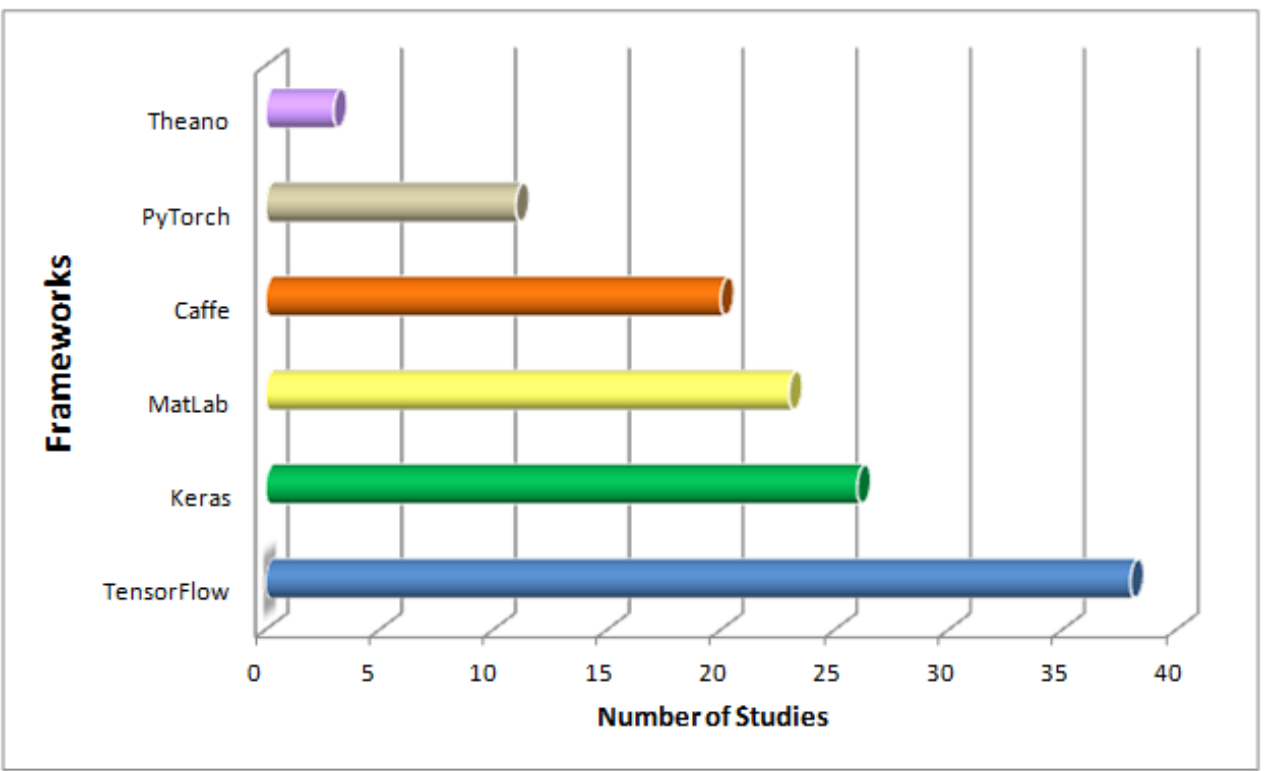

Figure 7: The most used frameworks among the 121 studies summarized 


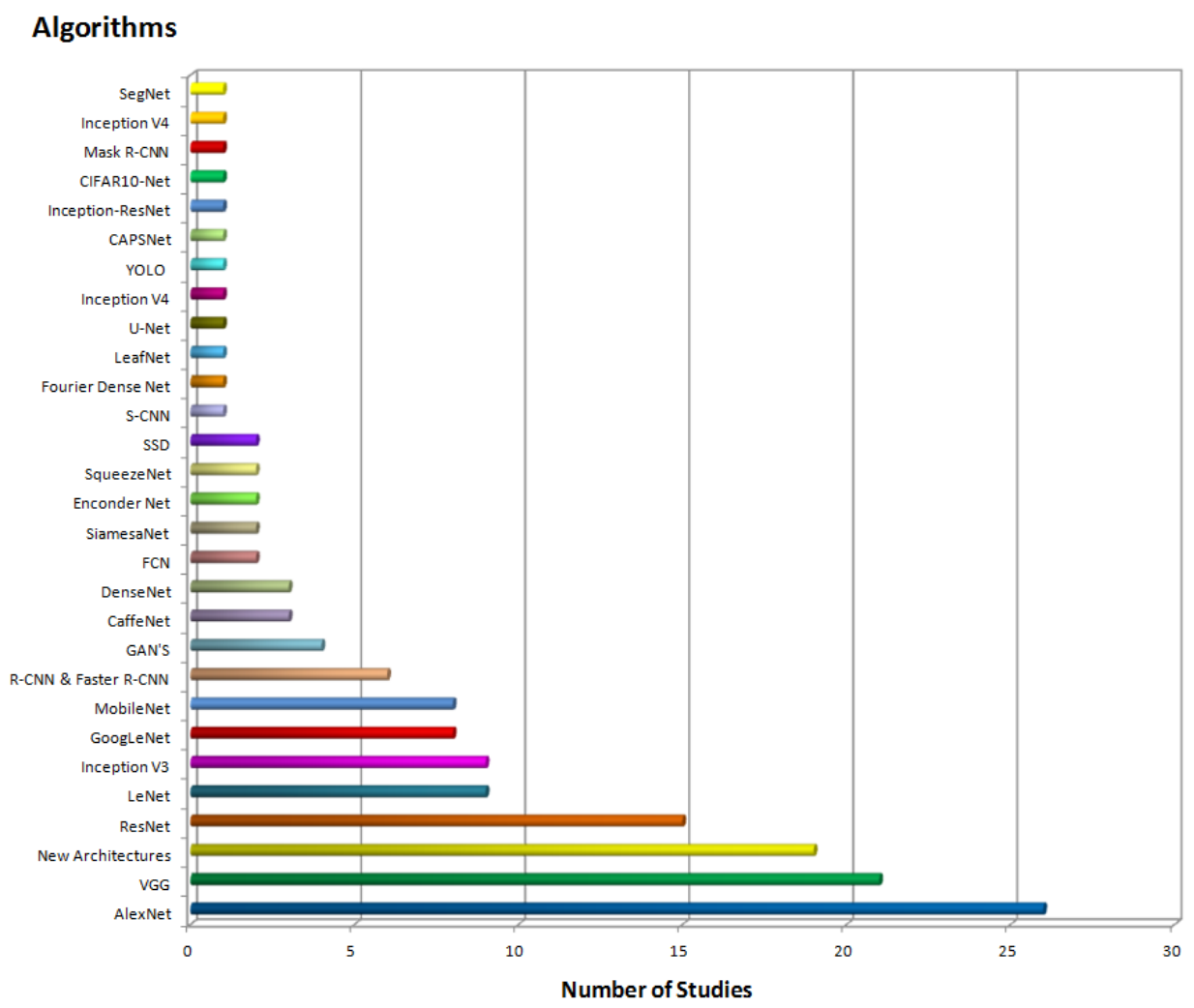

Figure 8: The CNN Algorithms most used in the 121 summarized studies

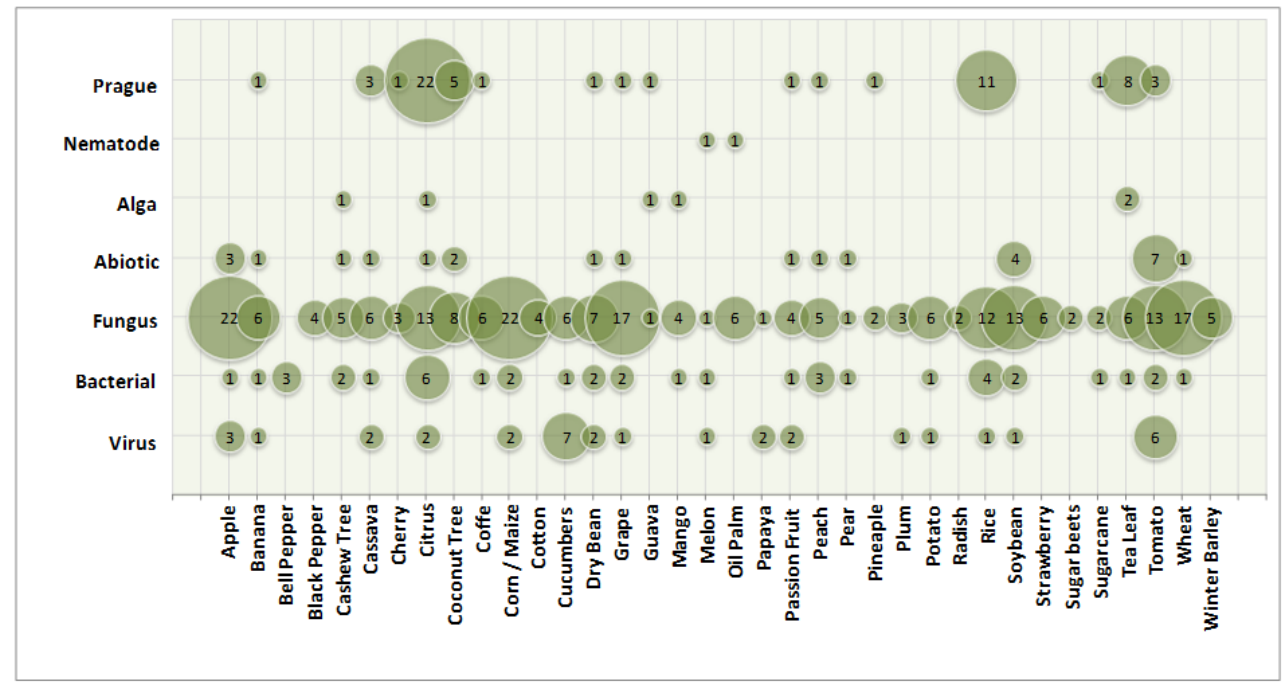

Figure 9: Relationship of type of crops X groups of pathogens $X$ occurrences of diseases investigated by causative agents

\section{Discussion}

To keep the discussion in line with the core questions, all of them answered in the previous section, our study is organized into four topics that describe state of the art on identifying plant diseases using CNNs. 


\subsection{Predominant Approaches}

Different innovations in CNN architectures have been proposed since 1998 with the presentation of LeNet-5[9] and can be categorized as parameter optimization, regularization, structural reformulation (Convolutional layer, Polling layer, and Activation Function), loss function and fast processing. However, it is observed that the main improvement in the performance of CNNs is motivated by the structural reformulation and design of new blocks [22].

When we tried to answer the question SQ1 of Section 4.1, we noticed that the investigations that applied state of the art for identification and classification of plant diseases using CNNs explored different innovative approaches to provide a reliable solution to the problem investigated.

As for the new architectures, we noticed three trends for the formulation of approaches. One of them is the structural reformulation of traditional architectures, such as LeNet (studies S61, S65, S68, S84, S100, S114, and S116), AlexNet (S113 and S120) and ResNet (S6, S43, S75, and S86). Among these, it is possible to highlight the S84 approach proposed by [35] that uses LeNet as an explainable model that can identify and quantify leaf tensions consistently, quickly, and accurately. The proposal seeks a solution for mobile platforms for detection in real-time with an accuracy of $95.04 \%$, aiming at a fast and large-scale observation of crops in real cultivation environments.

The S113 study proposed by [36] describes an approach for the classification and identification of four common diseases of apple leaves. The architecture achieves an overall accuracy of $97.62 \%$ and a significant reduction in the number of parameters compared to a standard AlexNet model. Another architecture based on ResNet, called HOResNet, is proposed in the study S86 de [37] aiming at a robust recognition of plant diseases. The research explores the problem of low precision in the identification and classification of plant diseases with images acquired in real crop environments. It improves the anti-interference ability by exploring images with sizes, shooting angles, poses, background, and lighting in different aspects. The results demonstrate that the approach reaches an accuracy of $91.79 \%$ and $90.14 \%$ to diseases of Tomato and Rice and Cucumbers, respectively.

Another trend is the blending of blocks between architectures, such as the S15 study (Yolo-DenseNet) and the S22 study (Inception-ResNet). In the [38] proposal of study S15, a CNN-based method of detecting anthracnose lesions is described using data augmentation techniques using Cycle-Consistent Adversarial Network (CycleGAN). This approach includes a DenseNet to optimize the resource layers of the YOLO-V3 model that have low resolution, reaching an accuracy of $95.57 \%$. The S22 study by [39] proposes a new deep convolutional neural network (DCNN) based approach for auTomatod crop disease detection using very high spatial resolution hyperspectral images captured with UAVs. The proposed model introduced multiple Inception-ResNet layers for feature extraction and was optimized to establish the most suitable depth and width of the network. The proposal deals with three-dimensional data, using spatial and spectral information to detect yellow rust in wheat with an accuracy of $85 \%$.

The latest trend includes proposals that implement architectures explicitly designed for the identification and classification of plant diseases, with emphasis on models that use hyperspectral images, namely: GPDCNN (S1), 3D-CNN (S7), PDDNN (S11), M-bCNN-CKM (S12), Teacher / Student Architecture (S13), PlantDiseaseNet (S35), Fourier Dense Network (S54) and OR-AC-GAN (S70).

In the S70 study proposed by [40], an approach called OR-AC-GAN is described, developed for the early detection of Tomato spotted wilt virus using hyperspectral images and an auxiliary external removal classifier using opposing generation networks. The proposal integrates the tasks of plant segmentation, spectrum classification, and image classification. The results showed that the accuracy reaches $96.25 \%$ before the visible symptoms appear. The approach proposed by [41] in study S7 projects a CNN architecture called supervised 3D-CNN based model to learn the spectral and spatial information of hyperspectral images for classification of healthy and charcoal rot infected samples. A saliency map-based visualization method is used to identify the hyperspectral wavelengths that make a significant contribution to classification accuracy. The model achieved a classification accuracy of $95.73 \%$.

\subsection{Characteristic of the Data Sets}

The characteristics of the data sets, such as the number of samples, number of diseases, symptomatic similarity caused by pathogens, pests, and abiotic factors, constitute one of the most important limitations regarding the accuracy of the approaches that implement the identification and classification of diseases of plants. Experimental results indicate that while the technical constraints linked to automatic plant disease classification have mainly been overcome, the use of limited image datasets for training brings many undesirable consequences that still prevent the effective dissemination of this type of technology [42].

The answer to question SQ2 from Section 4.2, groups the data sets with the highest recurrence in the studies, and demonstrates that the approaches try to reduce the limitations by creating customized sets that mix images from controlled environments with images captured under real growing conditions. However, we noticed that $65.28 \%$ of 
the approaches use sets with images in controlled environments, with PlantVillage being present in $37.19 \%$ of the summarized studies.

It should be noted that many approaches, such as studies S28, S35, S40, S65, S69, and S73, have already demonstrated a reduction in accuracy, when they use models trained exclusively with sets of images acquired in controlled environments to classify images in challenging conditions such as illumination, complex background, different resolution, size, pose, and orientation of real scene images. According to [43], who proposed the approach of the S28 study, when applying a customized CNN architecture, they obtained high precision with training and testing using the PlantVillage data set. However, the results obtained when applying the same network in images acquired in real crop conditions, there was a reduction of about $30 \%$ to $40 \%$ in the global accuracy.

\subsection{CNN Algorithms and Frameworks}

Among the summarized studies, TensorFlow [44] is the framework for creating and training CNN networks most used by approaches. Following this trend, Keras [45] is a high-level neural networks API, written in Python, and capable of running on top of TensorFlow, which demonstrates significant results regarding the implementation of approaches using CNNs.

As for the implementation of these CNN architectures, we note that traditional algorithms such as, for example, AlexNet, VGG, ResNet, LeNet, InceptionV3, GoogLeNet are predominant in the investigated studies. The recurring use of these implementations is explained by their success cases based on the ImageNet challenge [46]. Approximately $85 \%$ of the approaches use the transfer learning, fine tune, and hyperparameters methods to increase the accuracy of their results in detriment to the deficiencies of the data sets used. Additionally, it is possible to relate the recurrence of these traditional algorithms to a significant number of approaches. It makes these strategies such as layer customization, transfer learning, fine-tune, and hyperparameters groups with emphasis on the predominance of the investigated methods.

Still, regarding this relationship, we identified that the approaches that propose new architectures with significant advances regarding the implementation of CNNs sign a trend of investigation present in the studies.

\subsection{Types Crops and Disease Causing Pathogens}

The results showed that in addition to the approaches that investigate a diverse set of crops, tomatoes together with apples, corn, rice, cucumbers, wheat, grapes, potatoes, and bananas are the ones that concentrate the most significant number of investigations using CNNs. Taking as a concept that grains and cereals are the primary sources of energy ingested by humans, it was evident the lack of studies with approaches that primarily contemplated these crops.

In the case of soybeans, one of the main legumes of industrial interest, it was possible to identify only studies S7, S81, and S84. Highlighted is the approach proposed by [41] in study S7 that creates an architecture called 3D-CNN that can be used to extract features jointly across the spatial and spectral dimension for classification of a 3D hyperspectral data. The authors demonstrated that a 3D CNN model could be used effectively to learn from hyperspectral data to identify charcoal rot disease in soybean stems. They how to show that saliency map visualization can be used to explain the importance of specific hyperspectral wavelengths in the classification of the diseased and healthy soybean stem tissue.

When analyzing the results that deal with the types of plant diseases, we establish a relationship between the diseases investigated in the approaches with their causative agents. It was possible to observe that the vast majority of investigations identify and classify diseases caused by fungi. This fact can be explained because it is estimated that $70 \%$ of the main plant diseases are caused by this pathogen[20, 47].

The diseases caused by viruses and bacteria, although they do not have consistent quantitative approaches, are represented in a diversity of crops found in the data sets. The diseases caused by algae are represented by the crop Cashew, Citrus, Guava, Strawberries, and tea leaves. We also identified the classification of diseases caused by abiotic factors in investigations using CNNs.

The inexpressive number of approaches that classify diseases caused by nematodes caught our attention. These pathogens are considered to be one of the most significant phytosanitary risks in the main grain and cereal crops in the world. Indeed, the absence of investigations using CNNs to identify symptoms caused by nematodes is the symptomatic similarity of the characteristics presented by the plant with other diseases or particularities that are not visibly expressed in the leaves and stems of the plant. 


\section{Conclusion}

The automatized plant disease detection systems propose the identification and classification of plant diseases, reconciling the know-how of specialists in phytopathology and the ability to extract symptomatic features, through convolutional neural networks.

The diversity of problems and the specificities of real-world scenarios make it difficult to semantically catalog the data in representative sets with a sufficient number of labeled samples. This problem becomes a relevant and challenging bottleneck to make machine learning methods more applicable in practice.

Our results demonstrate the significant advances in the use of CNN in plant disease prediction processes. It was possible to observe that the traditional architectures combined with optimization and customization methods, despite the complexity of the data set composed with images captured in real environments of the crops, present relevant accuracy. The tendency of the may approaches that propose new CNN architectures based on the process of identifying plant diseases is growing, even presenting lower accuracy than the methods that use traditional architectures.

Finally, we also find that crops such as grains and cereals with high food and financial representativeness are often overlooked by the approaches. Also, we highlight the inexpressive number of methods that identify or classify diseases caused by nematodes.

The study of the works presented and the problems they propose to solve, together with the new trends in architecture of convolutional neural networks, aimed at the identification and classification of plant diseases. These techniques are combined with multispectral and hyperspectral images, which can lead to new solutions for agriculture, bringing production gains with the minimization of damages caused by biotic or abiotic agents. 
Plant Diseases recognition on images using Convolutional Neural Networks: A Systematic Review

A PREPRINT

\section{A Summarization}

Table 3: Characteristics of the Primary Studies of the Final Selection

\begin{tabular}{|c|c|c|c|c|c|c|c|c|c|c|}
\hline ID & Refs & Year & Io & Algorithm & $\begin{array}{l}\text { Best } \\
\text { Accuracy }\end{array}$ & Dataset Characterisitics & $\begin{array}{l}\text { Type of } \\
\text { Crops } \\
\end{array}$ & $\begin{array}{l}\text { Type of } \\
\text { Images }\end{array}$ & $\begin{array}{c}\begin{array}{c}\text { Language } \\
\& \text { Framework }\end{array} \\
\end{array}$ & Predominant Approach \\
\hline $\mathrm{si}$ & 48 & 2019 & 5 & GPDCNN & $94,65 \%$ & $\begin{array}{c}\text { Customized } \\
700 \text { Images } 7 \text { Class } \\
\text { Real Enviromment }\end{array}$ & Cucumbers & RGB & Tensorflow & New Architecture \\
\hline $\mathrm{s}_{2}$ & 49 & 2019 & 4,5 & $\begin{array}{l}\text { R-CNN \& } \\
\text { Faster R-CNN }\end{array}$ & $93,4 \%$ & $\begin{array}{c}\text { Customized } \\
335 \text { Images } / 3 \text { Class } \\
\text { Real Enviromment }\end{array}$ & Wheat & RGB & Tensorflow & Transfer Learning \\
\hline $\mathrm{s} 3_{3}$ & 50 & 2019 & 4,5 & s-CNN & $98,6 \%$ & 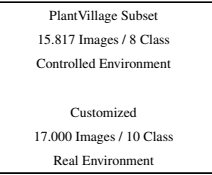 & Tomato & RGB & Tensorflow & Image Segmentation \\
\hline s4 & 51] & 2019 & 4,5 & ResNet & $98 \%$ & $\begin{array}{c}\text { PlantVillage } \\
32.933 \text { Images } 45 \text { Class } \\
\text { Controlled Enviromment }\end{array}$ & Diverse & RGB & PyTorch & $\begin{array}{l}\text { Fine Tune \& } \\
\text { Hyperparancers }\end{array}$ \\
\hline ss & $52]$ & 2019 & 4,5 & UNet + InceptionV3 & $87,45 \%$ & $\begin{array}{l}\text { Crop Discase AI Challenger } 2018 \\
40.000 \text { Images } 19 \text { Class } \\
\text { Controlled Environment }\end{array}$ & Diverse & RGB & Tensorflow & Image Segmentation \\
\hline s6 & {$[5]$} & 2019 & 4 & RESNET-MCI & $\begin{array}{l}98 \% \\
\text { BAC }\end{array}$ & $\begin{array}{c}\text { Customized } \\
121.955 \text { Images / 21 Class } \\
\text { Controlled Enviromente c Real }\end{array}$ & Diverse & RGB & Tensorflow/Keras & New Architecture \\
\hline S7 & 41] & 2019 & 4 & 3D-CNN & $95,73 \%$ & $\begin{array}{c}\text { Customized } \\
1.090 \text { Images /2 Class } \\
\text { Controlled Environment }\end{array}$ & Soybcan & Hyperspectral & Tensorflow/Keras & New Architecture \\
\hline s8 & 54 & 2019 & 4 & ResNet-Crowdsourced & $99,79 \%$ & $\begin{array}{c}\text { Customized } \\
15.240 \text { Images / } 2 \text { Class } \\
\text { Real Enviromment }\end{array}$ & Corn & RGB & Tensorflow & Image Segmentation \\
\hline s9 & 55 & 2019 & 4 & $\begin{array}{l}\text { Three Channel CNN } \\
\text { AlexNet }\end{array}$ & $\begin{array}{l}91,15 \% \\
94,27 \%\end{array}$ & $\begin{array}{c}\text { PlantVillage Subset } \\
15 \text {. Si7 I Images } / 8 \text { Class } \\
\text { COntrolled Enviroment } \\
\text { Customized } \\
500 \text { Images } / 5 \text { Class } \\
\text { Real Enviromment }\end{array}$ & Cucumbers & RGB & MatLab & Layers Custom \\
\hline s10 & 56 & 2019 & 4 & LeNet & $95,83 \%$ & $\begin{array}{l}\text { Rice Blass Disease } \\
5.808 \text { Images / } 2 \text { Class } \\
\text { Controlled Environment }\end{array}$ & Rice & RGB & PyTorch & Layers Custom \\
\hline s11 & 57 & 2019 & 4 & PDDNN & $86 \%$ & $\begin{array}{c}\text { PlantVillage } \\
14.810 \text { Images } 110 \text { Class } \\
\text { Controlled Enviromment }\end{array}$ & Diverse & RGB & Tensorflow & New Architecture \\
\hline $\mathrm{s} 12$ & 58 & 2019 & 4 & $\begin{array}{c}\text { M-bCNN-CKM } \\
\text { AlexNet } \\
\text { VGG } \\
\end{array}$ & $\begin{array}{l}96,5 \% \\
83,1 \% \% \\
88.5 \%\end{array}$ & $\begin{array}{c}\text { Customized } \\
16.652 \text { Images } / 8 \text { Class } \\
\text { Real Enviromment } \\
\end{array}$ & What & RGB & Tensorflow & New Architecture \\
\hline s13 & 59 & 2019 & 4 & $\begin{array}{l}\text { Teachers Sudent } \\
\text { Archicture }\end{array}$ & $\begin{array}{l}90,7 \% \\
\text { AOPC }\end{array}$ & $\begin{array}{c}\text { PlantVillage } \\
54.306 \text { Images } 38 \text { Class } \\
\text { Controlled Environment }\end{array}$ & Diverse & RGB & Tensorflow/Keras & New Architecture \\
\hline$\$ 14$ & 25 & 2019 & 4 & ResNet & $99,37 \%$ & $\begin{array}{c}\text { PlantVillage } \\
86.198 \text { Images } / 57 \text { Class } \\
\text { Controlled Enviromment }\end{array}$ & Diverse & RGB & Tensorflow & Transfer Learning \\
\hline s15 & 38 & 2019 & 4 & YoLov3 - DenseNet & $95,75 \%$ & $\begin{array}{c}\text { Customized } \\
640 \text { Images } / 2 \text { Class } \\
\text { Real Enviromment }\end{array}$ & Apple & RGB & Tensorflow & New Architecture \\
\hline
\end{tabular}


Plant Diseases recognition on images using Convolutional Neural Networks: A Systematic Review A PREPRINT

\begin{tabular}{|c|c|c|c|c|c|c|c|c|c|c|}
\hline \multicolumn{11}{|c|}{ Table 3 - continued from previous page } \\
\hline ID & Refs & Year & Ie & Algorithm & $\begin{array}{c}\begin{array}{c}\text { Best } \\
\text { Accuracy }\end{array} \\
\text { (a) }\end{array}$ & Dataset Characteristics & $\begin{array}{c}\begin{array}{c}\text { Type da } \\
\text { Crops }\end{array} \\
\end{array}$ & $\begin{array}{l}\begin{array}{c}\text { Type das } \\
\text { Images }\end{array} \\
\end{array}$ & $\begin{array}{c}\text { Linguagem } \\
\& \text { Framework }\end{array}$ & Predominant Approach \\
\hline s16 & 60 & 2019 & 4 & GoogLeNet & $94 \%$ & $\begin{array}{c}\text { PDDB Embrapa } \\
\text { 46.409 Images } 79 \text { Class } \\
\text { Real Enviromment }\end{array}$ & Diverse & RGB & Matuab & Transter Laarning \\
\hline s17 & 目 & 2019 & 4 & VGG16 Encoder & $96 \%$ & $\begin{array}{c}\text { Customized } \\
400 \text { Images / Class } \\
\text { Controlled Environment }\end{array}$ & Oilseds & RGB & MatLab & $\begin{array}{c}\text { Fine Tune \& } \\
\text { Image Segmentation } \\
\end{array}$ \\
\hline 518 & 62 & 2019 & 4 & MCNN - AlexNet & $97,13 \%$ & $\begin{array}{c}\text { PlantVillage Subset (1130) } \\
\text { Custom Mango Leaf (1070) } \\
2.200 \text { Images / 2 Class } \\
\text { Controlled Enviromment C Real }\end{array}$ & Mango & RGB & Tensorflow/Keras & Layers Custom \\
\hline$s 19$ & 63 & 2019 & 4 & $\begin{array}{l}\text { ResNet-B } \\
\text { VGG16 } \\
\text { InceptionV3 } \\
\text { MobilieNet }\end{array}$ & $\begin{array}{l}99,7 \% \\
94,7 \% \\
99,5 \% \\
99,6 \%\end{array}$ & $\begin{array}{c}\text { AI Challenger } \\
40.722 \text { Images } / 23 \text { Class } \\
\text { Controlled Environment }\end{array}$ & Diverse & RGB & PyTorch & Layers Custom \\
\hline 520 & 64 & 2019 & 4 & 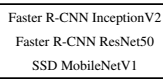 & $\begin{array}{l}99,0 \% \\
99,9 \% \\
98,2 \% \\
\end{array}$ & $\begin{array}{c}\text { Customized } \\
18.000 \text { Images } / 2 \text { Class } \\
\text { Real Enviromment } \\
\end{array}$ & Banana & RGB & Tensorflow/Keras & Layers Custom \\
\hline \$21 & 65 & 2019 & 3,5 & $\begin{array}{c}\text { MobilieNet } \\
\text { Recuce MobileNet }\end{array}$ & $\begin{array}{l}97,65 \% \\
98,34 \% \\
\end{array}$ & $\begin{array}{c}\text { PlantVililage } \\
54.306 \text { Images } 38 \text { Class } \\
\text { Controlled Enviromment } \\
\end{array}$ & Diverse & RGB & Tensorflow/Keras & Layers Custom \\
\hline $\mathrm{s} 22$ & 39] & 2019 & 3,5 & $\begin{array}{c}\text { DCNN } \\
\text { Inception-ResNet Block }\end{array}$ & $85,0 \%$ & $\begin{array}{c}\text { Customized } \\
15.000 \text { Images } / 2 \text { Class } \\
\text { Controlled Environment }\end{array}$ & Wheat & Hyperspectral & PyTorch & New Archicecture \\
\hline${ }_{523}$ & 66 & 2019 & 3.5 & DCNN based AlexNer & $99,11 \%$ & $\begin{array}{c}\text { Plantvililage } \\
54.306 \text { Images } / 38 \text { Class } \\
\text { Controlled Environment }\end{array}$ & Diverse & RGB & Tensorflow & Layers Custom \\
\hline $\mathbf{5} 24$ & 回 & 2019 & 3,5 & MobileNet & $91,0 \%$ & 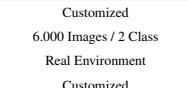 & Grape & RGB & Tensorflow/Keras & Transter Learning \\
\hline $\mathrm{s} 25$ & 68 & 2019 & 3,5 & SegnNet GANs & $\approx 64,3 \%$ & $\begin{array}{l}50 \text { Images } / 2 \text { Class } \\
\text { Real Environment } \\
\end{array}$ & Apple & Mullispectral & Tensorflow & Data Augmentation \\
\hline 526 & 回 & 2019 & 3,5 & AlexNet & $99,16 \%$ & $\begin{array}{c}\text { PlantVillagec Subset } \\
\text { 4063 Images } / \text { Class } \\
\text { Controlled Environment }\end{array}$ & Grape & RGB & MaLtab & Layers Custom \\
\hline \$27 & 70 & 2019 & 3,5 & $\begin{array}{l}\text { Convolutional } \\
\text { Enconder Network }\end{array}$ & $999 \%$ & $\begin{array}{c}\text { PlantVillage Subset } \\
900 \text { Images / 6Class } \\
\text { Controlled Environment }\end{array}$ & $\begin{array}{l}\text { Corn } \\
\text { Tomato } \\
\text { Potato }\end{array}$ & RGB & Python & $\begin{array}{l}\text { Layers Custom \& } \\
\text { Fine Tune \& Hyperparam }\end{array}$ \\
\hline 528 & 43 & 2019 & 3,5 & $\begin{array}{c}\text { RessNet } \\
\text { Siamesanet }\end{array}$ & $\begin{array}{l}98,0 \% \\
92,0 \%\end{array}$ & 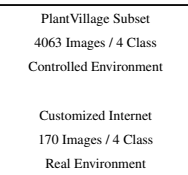 & Grape & RGB & Tensorflow & Layers Custom \\
\hline 529 & 四 & 2019 & 3,5 & IncepionV3 & $97,14 \%$ & $\begin{array}{c}\text { PlantViliage } \\
54.306 \text { Images } / 38 \text { Class } \\
\text { Controlled Enviromment }\end{array}$ & Diverse & RGB & Tensorflow/Keras & $\begin{array}{l}\text { Layers Custom } \\
75 \% \text { reduction in parameters }\end{array}$ \\
\hline $\mathrm{s} 30$ & [7] & 2019 & 3,5 & ResNet & $97,86 \%$ & $\begin{array}{c}\text { Turquia Customized } \\
1.965 \text { Images / } 8 \text { Class } \\
\text { Controlled Environment }\end{array}$ & Diverse & RGB & Maluab & Layers Custom \\
\hline $\mathrm{s} 31$ & 73 & 2019 & 3,5 & AlexNet & $98,74 \%$ & $\begin{array}{c}\text { BU-Guava- Leaf } \\
\text { 2.075 Images / C Cals } \\
\text { Controlled Enviromment } \\
\end{array}$ & Guava & RGB & Tensorflow/Keras & $\begin{array}{c}\text { Fine Tune \& } \\
\text { Hyperparameters }\end{array}$ \\
\hline
\end{tabular}


Plant Diseases recognition on images using Convolutional Neural Networks: A Systematic Review A PREPRINT

\begin{tabular}{|c|c|c|c|c|c|c|c|c|c|c|}
\hline ID & Refs & Year & 10 & Alporithm & Best & Datch & Type da & Type das & Linguagem & \\
\hline & ness & (t) & (l) & Agorithm & Accuracy & Dataset Characterstics & Crops & Images & \& Framework & Predominant Approach \\
\hline $\mathrm{s} 32$ & 74 & 2019 & 3,5 & VGG-INCEP & $97,14 \%$ & $\begin{array}{c}\text { ALDD } \\
\text { 26.37 Images / C Class } \\
\text { Real Environent }\end{array}$ & Apple & RGB & Caffe & Layers Custom \\
\hline 533 & 75 & 2019 & 3.5 & U-Net Segmentation & $96,08 \%$ & $\begin{array}{c}\text { Customized } \\
50 \text { I Images / } 2 \text { Class } \\
\text { Controlled Evirionment }\end{array}$ & Cucumbers & Multispectral & Tensorflow/Keras & $\begin{array}{l}\text { Data Augmentation \& } \\
\text { Image Segmentation }\end{array}$ \\
\hline$\$ 34$ & 76 & 2019 & 3,5 & Baseado LeNet & $91,0 \%$ & $\begin{array}{c}\text { Customized } \\
2000 \text { Images } / 4 \text { Class } \\
\text { Controlled Eviromment }\end{array}$ & Citus & RGB & Tensorflow/Keras & $\begin{array}{l}\text { Layers Custom \& } \\
\text { Data Augmentation }\end{array}$ \\
\hline $\mathrm{s} 35$ & 可 & 2019 & 3,5 & $\begin{array}{l}\text { PlanDDiscaseNet } \\
\text { Architecture }\end{array}$ & $93,67 \%$ & 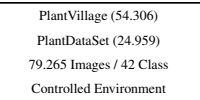 & Diverse & RGB & Tensorflow/Keras & New Architecture \\
\hline 536 & 78 & 2019 & 3,5 & vGG16 & $95,0 \%$ & $\begin{array}{c}\text { Customized } \\
124 \text { Images / } / 2 \text { Class } \\
\text { Controlled Environment }\end{array}$ & Millet & RGB & Tensorflow/Keras & Transfer Learning \\
\hline 537 & [7] & 2019 & 3.5 & $\mathrm{FCN}$ & $88.0 \%$ & $\begin{array}{c}\text { Customized } \\
22.000 \text { Images / } 2 \text { Class } \\
\text { Controlled Enviromment }\end{array}$ & Potato & Hyperspectral & PyyTorch & $\begin{array}{c}\text { Finc Tune \& } \\
\text { Hyperparameters \& } \\
\text { Image Segmentation }\end{array}$ \\
\hline 538 & 80 & 2019 & 3,5 & CIFAR-10Net & $95,5 \%$ & $\begin{array}{c}\text { Customized } \\
144 \text { Images } / 4 \text { Class } \\
\text { Real Enviromment }\end{array}$ & Tear Leaf & RGB & Tensorflow & Layers Custom \\
\hline \$39 & 81 & 2019 & 3,5 & $\begin{array}{l}\text { ROl-aware DCNN } \\
\text { Based VGG } \\
\end{array}$ & $84,3 \%$ & 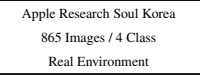 & Apple & RGB & Tensorflow & $\begin{array}{c}\text { Transfer Learning } \\
\text { \& Image Segmentation }\end{array}$ \\
\hline 540 & 82 & 2019 & 3,5 & MobileNet \& SSD & $75.0 \%$ & $\begin{array}{c}\text { IITA Cassava } \\
2.017 \text { Images } / 7 \text { Class } \\
\text { Controlled Environment } \\
\text { Customiced } \\
1.37 \text { Images } 7 \text { Class } \\
\text { Real Environment } \\
\end{array}$ & Cassara & RGB & Tensorflow & Transfer Learning \\
\hline 541 & 83 & 2019 & 3,5 & $\begin{array}{l}\text { Custom CNN } \\
\text { Based AlexNCet }\end{array}$ & $96,46 \%$ & $\begin{array}{c}\text { PlantVillage } \\
54.306 \text { Images } 3 \text { Class } \\
\text { Controlled Environment } \\
\end{array}$ & Diverse & RGB & Tensorflow/Keras & Layers Custom \\
\hline 542 & 84 & 2019 & 3 & Custom Inceppion & $91,7 \%$ & $\begin{array}{l}\text { IA Challenger Plant Leaf Disease } \\
4.523 \text { Images } 11 \text { Class } \\
\text { Controlled Evvironment }\end{array}$ & Diverse & RGB & Tensorflow & Layers Custom \\
\hline 543 & 85 & 2019 & 3 & $\mathrm{CNN} 50$ hidden layers & $92,85 \%$ & $\begin{array}{c}\text { Customized } \\
100 \text { II Images / } 3 \text { Class } \\
\text { Real Enviromment }\end{array}$ & Corn & RGB & Mataab & New Architecture \\
\hline 544 & 86 & 2019 & 3 & Mask R-CNN CResNel101 & $99,64 \%$ & $\begin{array}{c}\text { Customized } \\
1.430 \text { Images } / 11 \text { Class } \\
\text { Real Enviromment }\end{array}$ & Tomato & RGB & Tensorflow & Image Segmentation \\
\hline s45 & 87 & 2019 & 3 & Faster R-CNN & $95,48 \%$ & $\begin{array}{c}\text { Customized } \\
155 \text { Images } / 4 \text { Class } \\
\text { Real Enviromment }\end{array}$ & Sugar-beet & RGB & Matab & Layers Custom \\
\hline 546 & 88 & 2019 & 3 & Leanter & $99,84 \%$ & $\begin{array}{c}\text { Customized } \\
7.905 \text { Images } / 7 \text { Class } \\
\text { Controlled Environment }\end{array}$ & Tear Leaf & RGB & Mataab & $\begin{array}{c}\text { Fine Tune \& } \\
\text { Hyperparamelers }\end{array}$ \\
\hline 547 & 8 & 2019 & 3 & ResNel-34 & $95,1 \%$ & $\begin{array}{c}\text { Customized } \\
6.267 \text { Images / } 2 \text { classses } \\
\text { Real Enviromment } \\
\end{array}$ & Corn & RGB & PyTorch & $\begin{array}{c}\text { Fine Tune \& } \\
\text { Hyperparamelers }\end{array}$ \\
\hline s48 & 回 & 2019 & 3 & LeNet & $99,84 \%$ & $\begin{array}{l}\text { PlantVillage Subset } \\
9.000 \text { Images } / 6 \text { Class } \\
\text { Controlled Environment }\end{array}$ & Tomato & RGB & Caffe & Layers Custom \\
\hline
\end{tabular}


Plant Diseases recognition on images using Convolutional Neural Networks: A Systematic Review A PREPRINT

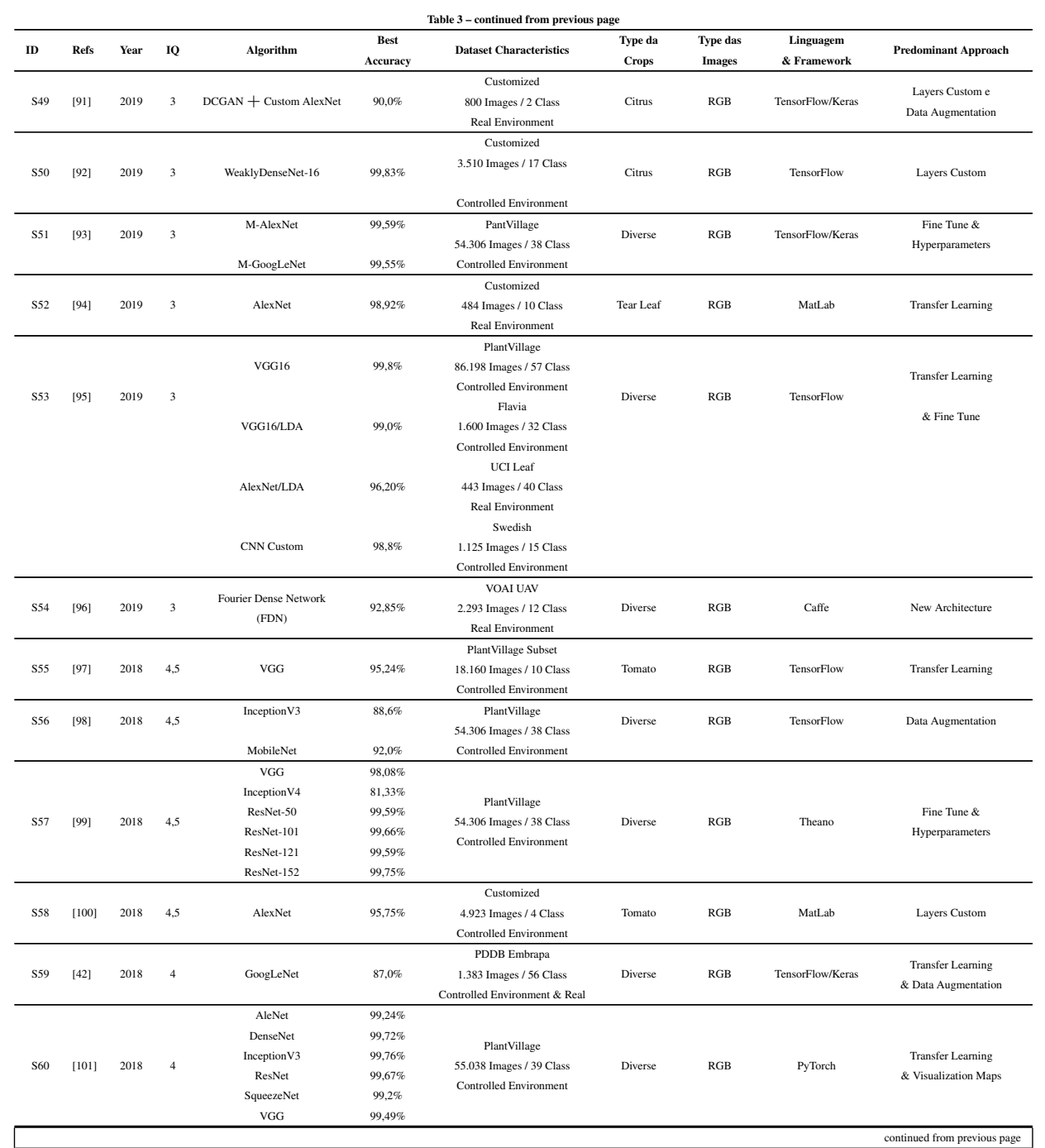


Plant Diseases recognition on images using Convolutional Neural Networks: A Systematic Review A PREPRINT

\begin{tabular}{|c|c|c|c|c|c|c|c|c|c|c|}
\hline \multicolumn{11}{|c|}{ continued from previou } \\
\hline ID & Refs & Year & Io & Algorithm & $\begin{array}{c}\text { Best } \\
\text { Accuracy }\end{array}$ & Dataset Characteristics & $\begin{array}{l}\text { Type da } \\
\text { Crops }\end{array}$ & 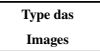 & $\begin{array}{l}\text { Linguagem } \\
\text { \& Framework }\end{array}$ & Predominant Approach \\
\hline s61 & {$[102$} & 2018 & 4 & Based LeNet + Lve & $86,0 \%$ & $\begin{array}{l}\text { PlantVililage Subset } \\
500 \text { Images / S Class } \\
\text { Controlled Environment }\end{array}$ & Tomato & RGB & Tensorflow & New Architecture \\
\hline $\mathrm{s} 62$ & 103 & 2018 & 4 & $\begin{array}{l}\text { AlexNet } \\
\text { GoogLeNet } \\
\text { VGG }\end{array}$ & $\begin{array}{l}99,44 \% \% \\
97,7 \% \% \\
99,48 \% \%\end{array}$ & $\begin{array}{c}\text { PlantVillage } \\
87.448 \text { Images } / 58 \text { Class } \\
\text { Controlled Enviromment }\end{array}$ & Diverse & RGB & Tensorflow & Transter Learning \\
\hline 563 & 104 & 2018 & 4 & $\begin{array}{l}\text { CNN Generative } \\
\text { Adversario Networks } \\
\text { DCGNAS }\end{array}$ & $89,93 \%$ & $\begin{array}{c}\text { PlantVillage } \\
54.306 \text { Images } / 38 \text { Class } \\
\text { Controlled Environment }\end{array}$ & Diverse & RGB & Tensorflow & Unsupervised Learning \\
\hline 564 & 1005 & 2018 & 4 & MobileNet & $89,0 \%$ & $\begin{array}{l}\text { Customized \& PDDS } \\
6.970 \text { Images } / 6 \text { Class } \\
\text { Controlled Enviromment }\end{array}$ & Diverse & RGB & Tensorflow & $\begin{array}{c}\text { Finc Tune \& } \\
\text { Hyperparameters \& } \\
\text { Data Augnentation } \\
\end{array}$ \\
\hline s65 & 100 & 2018 & 4 & Baseado LeNet & $78,0 \%$ & $\begin{array}{c}\text { Saitama Ressearch Center } \\
960.000 \text { Images } / 2 \text { Class } \\
\text { Controlled Environment \& Real }\end{array}$ & Cucumbers & RGB & Tensorflow & New Architecture \\
\hline 566 & 107 & 2018 & 3,5 & AutoEnconder CNN & $\begin{array}{l}87,01 \% \\
80,42\end{array}$ & $\begin{array}{l}\text { PlantVillage Subset } \\
6.004 \text { Images } / 7 \text { Class } \\
\text { Controlled Environment }\end{array}$ & $\begin{array}{l}\text { Potato } \\
\text { Corn }\end{array}$ & RGB & Tensorflow & Unsupervised Lcarning \\
\hline S67 & 1008 & 2018 & 3,5 & ResNet (SGD) & $96.51 \%$ & \begin{tabular}{|l|} 
Plantvillage Subset \\
5.50 Images 8 C Class \\
Controlled Enviromment \\
\end{tabular} & Tomato & RGB & Mataab & $\begin{array}{c}\text { Finc Tune \& } \\
\text { Hyperparameters \& } \\
\text { Data Augnentation } \\
\end{array}$ \\
\hline 568 & 100 & 2018 & 3,5 & Based LeNet & $90.84 \%$ & $\begin{array}{c}\text { PlantVillage Subser (4.123) } \\
\text { Customized (2.430) } \\
6.553 \text { Images / 8 Class } \\
\text { Controlled Environment \& Real }\end{array}$ & 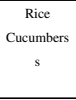 & RGB & Tensorflow & New Architecture \\
\hline 569 & [110] & 2018 & 3,5 & Inceppionv3 & $92,7 \%$ & $\begin{array}{c}\text { PantVillage } \\
54.306 \text { Images } / 38 \text { Class } \\
\text { Controlled Enviroment } \\
\text { Cussomized }\end{array}$ & Diverse & RGB & Tensorflow & Transter Learning \\
\hline & & & & & $82,7 \%$ & $\begin{array}{l}1966 \text { Images / Class } \\
\text { Real Enviroment } \\
\text { Customized }\end{array}$ & Mango & & & \\
\hline & & & & & ${ }_{92,8 \%}$ & $\begin{array}{l}811 \text { Imagermesced } / 3 \text { Class } \\
\text { Real Enviromment }\end{array}$ & Peanut & & & \\
\hline 570 & 40 & 2018 & 3,5 & OR-AC-GAN & $98,03 \%$ & $\begin{array}{c}\text { Customized } \\
601 \text { Images } / 2 \text { Class } \\
\text { Controlled Enviromment }\end{array}$ & Peppers & Hyperspectral & Tensorflow & New Archiecture \\
\hline 571 & 囵 & 2018 & 3,5 & GoogleNer & $98,9 \%$ & $\begin{array}{c}\text { Customized } \\
500 \text { Images / } 9 \text { Class } \\
\text { Controlled Environment }\end{array}$ & Corn & RGB & Caffe & Layers Custom \\
\hline 572 & {$[112$} & 2018 & 3,5 & Inceppionv3 & $93,0 \%$ & $\begin{array}{l}\text { PlantVillage Subset } \\
9.568 \text { Inages } 11 \text { Class } \\
\text { Controlled Environment }\end{array}$ & Apple & RGB & Tensorflow/Keras & $\begin{array}{l}\text { Transfer Learning } \\
\& \text { Data Augmentation }\end{array}$ \\
\hline 573 & $\square 113$ & 2018 & 3,5 & GoogLLNer & $87,0 \%$ & $\begin{array}{c}\text { PlantVillage Subse \& } \\
\text { Customized } \\
10.441 \text { Images } 10 \text { Class } \\
\text { Controlled Environment \& Real }\end{array}$ & Corn & RGB & MatLab & Transfer Learning \\
\hline 574 & 1114 & 2018 & 3,5 & VGG & $96,0 \%$ & $\begin{array}{c}\text { Customized } \\
2.639 \text { Images } 4 \text { Class } \\
\text { Controllded Enviromment }\end{array}$ & Apple & Hyperspectral & Tensorflow/Keras & Layers Custom \\
\hline 575 & [115 & 2018 & 3,5 & $\begin{array}{l}\text { Refinement Filter Bank } \\
\text { Basecd Res Cet }\end{array}$ & $96,0 \%$ & $\begin{array}{c}\text { Customized } \\
8.927 \text { Images } 110 \text { Class } \\
\text { Controlled Environment \& Real }\end{array}$ & Tomato & RGB & Caffe & New Architecture \\
\hline
\end{tabular}


Plant Diseases recognition on images using Convolutional Neural Networks: A Systematic Review A PREPRINT

\begin{tabular}{|c|c|c|c|c|c|c|c|c|c|c|}
\hline ID & Refs & Year & Io & Algorithm & Best & Dataset Characteristics & Type da & $\begin{array}{l}\text { Type das } \\
\end{array}$ & Linguagem & Predominant $\mathrm{Approach}$ \\
\hline & & & & & & $\begin{array}{l}\text { PlantVillage } \\
\end{array}$ & & & \& Framework & \\
\hline 576 & [116] & 2018 & ${ }^{3}$ & AlexNet & $95,93 \%$ & $\begin{array}{l}54.306 \text { Images } / 38 \text { Class } \\
\text { Controlled Enviromment }\end{array}$ & Diverse & RGB & Tensorflow & Transfer Learning \\
\hline 577 & 1117 & 2018 & 3 & ResNet & $96,0 \%$ & $\begin{array}{l}\text { Customiced } \\
\text { 8.178 mages } 4 \text { Class } \\
\text { Real Enviromment }\end{array}$ & Wheat & RGB & Tensorflow & $\begin{array}{l}\text { Layers Cusuom \& } \\
\text { Images cegencuntaion }\end{array}$ \\
\hline S78 & 118 & 2018 & 3 & LeNet & $94,85 \%$ & $\begin{array}{l}\text { PlantVillage Subset } \\
18.16 \text { Images } 110 \text { Class } \\
\text { Controlled Enviromment }\end{array}$ & Tomato & RGB & Tensorflow/Keras & Layers Custom \\
\hline S79 & 1119 & 2018 & 3 & ResNet (PENLU) & $98,3 \%$ & $\begin{array}{c}\text { Customized } \\
960 \text { Images /3 Class } \\
\text { Real Enviromment }\end{array}$ & Citus & RGB & Caffe & Layers Custom \\
\hline s80 & {$[20]$} & 2018 & 3 & R-CNN & $95,0 \%$ & $\begin{array}{c}\text { Customized } \\
10.744 \text { Images } \\
\text { Controlled Enviromment } \\
\end{array}$ & Corn & Hyperspectral & Caffe & Image Segmentation \\
\hline $\mathrm{s81}$ & [12] & 2018 & 3 & LeNet & $99,32 \%$ & $\begin{array}{l}\text { PlannVillage Subset } \\
12.673 \text { Images / } 4 \text { Class } \\
\text { Controlled Environment }\end{array}$ & Soybean & RGB & Tensorflow & Layers Custom \\
\hline $\mathrm{s} 82$ & 122 & 2018 & 3 & GoogLeNet & $90,0 \%$ & $\begin{array}{c}\text { Customized } \\
40 \text { Images } \\
1550 \text { RoI } / \text { Class } \\
\text { Controlled Enviromment }\end{array}$ & Radish & RGB & PyTorch & $\begin{array}{c}\text { Fine Tune \& } \\
\text { Hyperparameters \& } \\
\text { Image Seggnentation }\end{array}$ \\
\hline 583 & 123 & 2018 & 3 & vGG & $99,04 \%$ & $\begin{array}{l}\text { Pest Image Dataset } \\
32.000 \text { Images } 32 \text { Class } \\
\text { Controlled Eviromment } \\
\end{array}$ & Diverse & RGB & Tensorflow/Keras & Layers Custom \\
\hline 584 & 35] & 2018 & 3 & $\begin{array}{l}\text { CNN XPLNet } \\
\text { Based LeNeet }\end{array}$ & $95,04 \%$ & $\begin{array}{c}\text { Customized } \\
25.000 \text { Images } / 7 \text { Class } \\
\text { Controlled Enviromment }\end{array}$ & Soybean & RGB & PyTorch & New Architecture \\
\hline s85 & 124 & 2018 & ${ }^{3}$ & vGG & $98,6 \%$ & $\begin{array}{c}\text { PlantVillage Subset } \\
\text { CASC-IFW } \\
6.309 \text { Images / } 6 \text { Class } \\
\text { Controlled Enviromment }\end{array}$ & $\begin{array}{c}\text { Banana a } \\
\text { Apple } \\
\text { A }\end{array}$ & Multispectral & Caffe & $\begin{array}{c}\text { Transfer Learning } \\
\& \text { Fine Tune }\end{array}$ \\
\hline 586 & 37] & 2018 & 3 & $\begin{array}{c}\text { HoResNet } \\
\text { Bascd ResNert }\end{array}$ & $\begin{array}{l}91,79 \% \% \\
90,14 \%\end{array}$ & 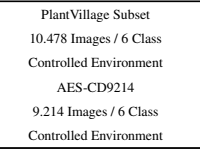 & $\begin{array}{l}\text { Tomato } \\
\text { Rice }\end{array}$ & RGB & Tensorflow & New Architecture \\
\hline s87 & [125] & 2018 & 3 & Caffenet & $87,0 \%$ & $\begin{array}{c}\text { Customized } \\
4.511 \text { Images } 113 \text { Class } \\
\text { Real Enviromment } \\
\end{array}$ & Rice & RGB & Caffic & Data Augmentation \\
\hline 588 & {$[26$} & 2018 & 3 & MobileNet & $65,93 \%$ & \begin{tabular}{|c|} 
Customized Fungos \\
122 Images $/ 2$ Class \\
Conrolled Enviromment \\
\end{tabular} & Banana & Micrsscopic & Tensorflow/Keras & $\begin{array}{c}\text { Finc Tune \& } \\
\text { Hyperparameters \& } \\
\text { Data Auggentation }\end{array}$ \\
\hline 589 & 1227 & 2018 & 3 & AlexNet & $93,4 \%$ & $\begin{array}{c}\text { Customized } \\
1.184 \text { Images } / 5 \text { Class } \\
\text { COntrolled Environment \& Real } \\
\end{array}$ & Cuumbers & RGB & Matalab & $\begin{array}{l}\text { Images Segmentation } \\
\text { \& Data Augmentation }\end{array}$ \\
\hline 590 & 228 & 2018 & 3 & AlexNet & $91,23 \%$ & $\begin{array}{c}\text { Customized } \\
600 \text { Images } / 3 \text { Class } \\
\text { Controlled Evvironment }\end{array}$ & Rice & RGB & Matabab & Transfer Learning \\
\hline s91 & [129] & 2018 & 3 & $\begin{array}{l}\text { Based VGG16 } \\
\text { Stackeded Mobile }\end{array}$ & $95,0 \%$ & $\begin{array}{l}\text { Customized } \\
1.426 \text { magases } 9 \text { Class } \\
\text { Real Enviromment } \\
\end{array}$ & Rice & RGB & Tensorflow/Keras & New Architecture \\
\hline
\end{tabular}


Plant Diseases recognition on images using Convolutional Neural Networks: A Systematic Review A PREPRINT

\begin{tabular}{|c|c|c|c|c|c|c|c|c|c|c|}
\hline \multirow[b]{2}{*}{ ID } & \multirow[b]{2}{*}{ Refs } & \multirow[b]{2}{*}{ Year } & \multirow[b]{2}{*}{ IQ } & \multirow[b]{2}{*}{ Algorithm } & \multicolumn{3}{|c|}{ Table 3 - continued from prexious page } & \multirow{2}{*}{$\begin{array}{l}\begin{array}{c}\text { Type das } \\
\text { Images }\end{array} \\
\text { Imes }\end{array}$} & \multirow[b]{2}{*}{$\begin{array}{c}\text { Linguagem } \\
\& \text { \&ramework }\end{array}$} & \multirow[b]{2}{*}{ Predominant Approach } \\
\hline & & & & & $\begin{array}{c}\text { Best } \\
\text { Accuracy }\end{array}$ & Dataset Characteristics & $\begin{array}{l}\frac{7 y p e \text { da }}{\text { Trops }} \\
\text { Con }\end{array}$ & & & \\
\hline 592 & 130 & 2018 & 3 & vGG & $96,0 \%$ & $\begin{array}{c}\text { Customized } \\
493 \text { Images /5 Class } \\
\text { Controlled Environment }\end{array}$ & Potato & RGB & Matab & $\begin{array}{c}\text { Fine Tun \& \& } \\
\text { Hyperparameters }\end{array}$ \\
\hline 593 & 131 & 2018 & 3 & $\begin{array}{l}\text { AlexNet } \\
\text { vGG16 }\end{array}$ & $\begin{array}{l}97,49 \% \\
97,23 \%\end{array}$ & 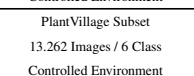 & Tomato & RGB & Matab & $\begin{array}{l}\text { Transfer Learning } \\
\& \text { \& Fine Tune }\end{array}$ \\
\hline 594 & 132 & 2018 & 3 & VGG \& F-RCNN & $69,79 \%$ & $\begin{array}{l}\text { TRES Taiwan Tea Research } \\
1.269 \text { Images } / 3 \text { Class } \\
\text { Controlled Environment }\end{array}$ & Tear Laaf & RGB & Caffe & Image Segmentation \\
\hline 595 & 133 & 2018 & 3 & CaspNet & $\mathrm{N} / \mathrm{A}$ & $\begin{array}{c}\text { Customized UAV } \\
500 \text { Images / / Class } \\
\text { Controlled Environment }\end{array}$ & Rice & RGB & MatLab & Image Segmentation \\
\hline 596 & [134 & 2018 & 3 & AlexNet & $96,0 \%$ & $\begin{array}{c}\text { Customized } \\
750 \text { Images } / 6 \text { Class } \\
\text { Controlled Environment }\end{array}$ & Corn & RGB & Matab & $\begin{array}{c}\text { Fine Tune } \\
\& \text { Image Scgmentation }\end{array}$ \\
\hline S97 & 135 & 2018 & 3 & LeNet-5 & $95,8 \%$ & $\begin{array}{c}\text { Customized UAV } \\
70.560 \text { Images / Class } \\
\text { Controlled Environment }\end{array}$ & Grape & RGB & Mataab & Image Segmentation \\
\hline s98 & 136 & 2018 & 3 & VGG & $93,6 \%$ & $\begin{array}{c}\text { Customized } \\
9.000 \text { Images } / 9 \text { Class } \\
\text { Controlled Enviromment }\end{array}$ & Cucumbers & RGB & Caffe & Transfer Learning \\
\hline 599 & 137 & 2017 & 4,5 & $\begin{array}{l}\text { AlexNet } \\
\text { Squecerencet }\end{array}$ & $\begin{array}{l}95,65 \% \\
94,3 \%\end{array}$ & $\begin{array}{c}\text { PlantVillage } \\
54.306 \text { Images } / 38 \text { Class } \\
\text { Controlled Environment }\end{array}$ & Tomato & RGB & Caffe & Transfer Learning \\
\hline$s 100$ & 138 & 2017 & 4 & Based LeNet & $95,48 \%$ & $\begin{array}{c}\text { Customized } \\
500 \text { Images } 110 \text { Class } \\
\text { Controlled Environment }\end{array}$ & Rice & RGB & PyTorch & New Architecture \\
\hline s101 & 139 & 2017 & 4 & VGG & $90,4 \%$ & $\begin{array}{l}\text { PlantVillage Subset } \\
2.086 \text { Images } / 4 \text { Class } \\
\text { Controlled Environment }\end{array}$ & Apple & RGB & Theano & $\begin{array}{c}\begin{array}{c}\text { Finc Tune \& } \\
\text { Hyperparamelers }\end{array}\end{array}$ \\
\hline s102 & 140 & 2017 & 4 & R-FCN \& ResNet & $85,98 \%$ & $\begin{array}{c}\text { Customized } \\
5.000 \text { Images } / 9 \text { Class } \\
\text { Controlled Environment }\end{array}$ & Tomato & RGB & Tensorflow/Keras & Data Augmentation \\
\hline s103 & [14] & 2017 & 4 & Based AlexNet & $97,8 \%$ & $\begin{array}{c}\text { Customized } \\
1.796 \text { Images } / 2 \text { Class } \\
\text { Controlled Environment }\end{array}$ & Corn & RGB & Theano & Image Segmentation \\
\hline s104 & 142] & 2017 & 3,5 & LeNet & $89,7 \%$ & $\begin{array}{c}\text { Customized } \\
1500 \text { Images } / 4 \text { Class } \\
\text { Controlled Enviromment }\end{array}$ & Strawberry & RGB & Tensorflow & Layers Custom \\
\hline s105 & 143 & 2017 & 3.5 & ResNet & $97,57 \%$ & $\begin{array}{l}\text { PlannVillage Subset } \\
19.72 \text { Images } 11 \text { Class } \\
\text { Controlled Enviromment } \\
\end{array}$ & Tomato & RGB & Caffe & Layers Custom \\
\hline s106 & 144 & 2017 & 3.5 & Inception V3 & $98,0 \%$ & $\begin{array}{c}\text { Original Cassava (2.756) } \\
\text { Leaf Cassava (15.000) } \\
\text { Controlled Environment \& Real }\end{array}$ & Cassava & RGB & Tensorflow & Transfer Learning \\
\hline$\$ 107$ & 1145 & 2017 & 3,5 & FCN & $87.5 \%$ & $\begin{array}{c}\text { Customized } \\
546 \text { Images } / 2 \text { Class } \\
\text { Controlled Environment }\end{array}$ & Apple & RGB & Caffe & Image Segmentation \\
\hline sios & 146 & 2017 & 3 & AlexNer & $78 \%$ & $\begin{array}{l}\text { PlantVillage Subset } \\
18.149 \text { Images } / 9 \text { Class } \\
\text { Controlled Enviromment }\end{array}$ & Tomato & RGB & Matabab & $\begin{array}{l}\text { Finc Tune \& } \\
\text { Hyperparameterss }\end{array}$ \\
\hline s109 & 147 & 2017 & 3 & Incepiion-ResNel V2 & $98,8 \%$ & $\begin{array}{l}\text { Mididle European Wood } \\
9.745 \text { Images } 153 \text { Class } \\
\text { Conrolled Environment }\end{array}$ & Diverse & RGB & PyTorch & $\begin{array}{l}\text { Fine Tunc \& } \\
\text { Layers Custom }\end{array}$ \\
\hline
\end{tabular}


Plant Diseases recognition on images using Convolutional Neural Networks: A Systematic Review A PREPRINT

\begin{tabular}{|c|c|c|c|c|c|c|c|c|c|c|}
\hline ID & Refs & $\begin{array}{l}\text { Year } \\
\end{array}$ & Io & Algorithm & $\begin{array}{l}\text { Best } \\
\text { Accuracy }\end{array}$ & Dataset Characteristics & $\begin{array}{l}\text { Type da } \\
\text { Crops }\end{array}$ & $\begin{array}{l}\text { Type das } \\
\text { Images }\end{array}$ & $\begin{array}{c}\text { Linguagem } \\
\text { \& Framework }\end{array}$ & Predominant Approach \\
\hline & & & & & $97,1 \%$ & $\begin{array}{c}\text { Austrian Federal Forest (AFF) } \\
134 \text { I Images / Class } \\
\text { Controlled Environment }\end{array}$ & & & & \\
\hline & & & & & $99,4 \%$ & $\begin{array}{l}\text { Flavia leaf Dataset } \\
1907 \text { Images / } / 2 \text { Class } \\
\text { Controlled Enviromment }\end{array}$ & & & & \\
\hline & & & & & $99,2 \%$ & $\begin{array}{l}\text { Foliage Leaf Dataset } \\
6.000 \text { I Images } / 60 \text { Class } \\
\text { Controlled Environment }\end{array}$ & & & & \\
\hline & & & & & $99,7 \%$ & $\begin{array}{l}\text { Swedish Leaaf Dataser } \\
1.125 \text { I Images } 115 \text { Class }\end{array}$ & & & & \\
\hline & & & & & $81,2 \%$ & 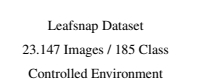 & & & & \\
\hline s110 & 148 & 2017 & 3 & LeNet \& GANs & $78 \%$ & 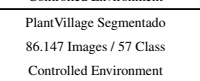 & Diverse & RGB & Tensorflow & Layers Custom \\
\hline s111 & [149 & 2017 & 3 & LeNet & $89,6 \%$ & $\begin{array}{c}\text { BjfuGlioxinia } \\
\text { 321 Images / 3 Class } \\
\text { Controlled Environment }\end{array}$ & Flowers & RGB & Tensorflow/Keraas & Layers Custom \\
\hline s112 & 150 & 2017 & 3 & VGG & $97,4 \%$ & $\begin{array}{c}\text { Customized } \\
1.734 \text { Images } / 4 \text { Class } \\
\text { Real Enviroument }\end{array}$ & Radish & RGB & Caffe & Layers Custom \\
\hline s113 & 36 & 2017 & 3 & Bascd AlexNet & $97,62 \%$ & $\begin{array}{c}\text { Customized } \\
13.699 \text { Images / Class } \\
\text { Controlled Enviromente }\end{array}$ & Apple & RGB & Caffe & New Archilecture \\
\hline s114 & 151 & 2017 & 3 & Based LeNet & $92,88 \%$ & $\begin{array}{l}\text { Plannvillage Subset } \\
\text { 3.700 IImages } 3 \text { Class } \\
\text { Controlled Enviromment }\end{array}$ & Banana & RGB & Matabab & New Architecture \\
\hline s115 & [152] & 2016 & 4,5 & Caffenet & $96,3 \%$ & $\begin{array}{c}\text { Customized } \\
4.483 \text { Images } 115 \text { Class } \\
\text { Controlled Eniromment }\end{array}$ & Diverse & RGB & Caffe & $\begin{array}{c}\text { Fine Tun \& \& } \\
\text { Hyperparameters }\end{array}$ \\
\hline s116 & 153 & 2016 & 4 & Based LeNet & $95,5 \%$ & $\begin{array}{c}\text { Customized } \\
400 \text { Images } \\
\text { Controlled Environment }\end{array}$ & Apple & RGB & MaLab & New Architecture \\
\hline s117 & 2] & 2016 & 3,5 & $\begin{array}{l}\text { AlexNet } \\
\text { GoogLLNetet }\end{array}$ & $\begin{array}{l}99,27 \% \\
97,24 \%\end{array}$ & $\begin{array}{c}\text { PlantVillage } \\
54.306 \text { Images } / 38 \text { Class } \\
\text { Controlled Environment }\end{array}$ & Diverse & RGB & Caffe & Transter Learning \\
\hline s118 & 154 & 2016 & 3 & AlexNet & $97,3 \%$ & $\begin{array}{l}\text { TreeApple Embrapa } \\
1.450 \text { Images / C Class } \\
\text { Controlled Environment }\end{array}$ & Apple & RGB & Tensorflow/Keras & $\begin{array}{l}\begin{array}{c}\text { Fine Tune \& } \\
\text { Hyperparanceters }\end{array} \\
\end{array}$ \\
\hline s119 & 155 & 2016 & 3 & VGG & $82,9 \%$ & 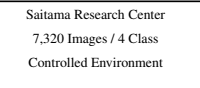 & Cuumbers & RGB & Caffe & $\begin{array}{l}\text { Layers Custom \& } \\
\text { Data Augmentation }\end{array}$ \\
\hline & & & & AlexNet & $75,05 \%$ & $\begin{array}{c}\text { Customized } \\
7.520 \text { Images / } 4 \text { Class } \\
\text { Controlled Environment \& Real }\end{array}$ & & & & \\
\hline
\end{tabular}


Plant Diseases recognition on images using Convolutional Neural Networks: A Systematic Review A PREPRINT

\begin{tabular}{|c|c|c|c|c|c|c|c|c|c|c|}
\hline \multicolumn{11}{|c|}{ Table 3 - continued from prexious page } \\
\hline ID & Refs & Year & Ie & Algorithm & $\begin{array}{c}\text { Best } \\
\text { Accuracy }\end{array}$ & Dataset Characteristics & $\begin{array}{l}\text { Type da } \\
\text { Crops }\end{array}$ & $\begin{array}{l}\text { Type das } \\
\text { Images }\end{array}$ & $\begin{array}{c}\text { Linguagem } \\
\text { \& Framework }\end{array}$ & Predominant Approach \\
\hline s120 & 156 & 2016 & 3 & Based AlexNel & $97,24 \%$ & $\begin{array}{c}\text { Flavia } \\
1.907 \text { Images } / 32 \text { Class } \\
\text { Controlled Environment }\end{array}$ & Diverse & RGB & Matabab & New Archilecture \\
\hline & & & & & $99,11 \%$ & $\begin{array}{c}\text { Swedish } \\
75 \text { Images } 15 \text { Class } \\
\text { Controlled Environment }\end{array}$ & & & & \\
\hline$\$ 121$ & 157] & 2015 & 4,5 & CaffeNet & $94,9 \%$ & $\begin{array}{c}\text { Customized } \\
800 \text { Images } / 3 \text { Class } \\
\text { Controlled Environment }\end{array}$ & Cuumbers & RGB & Caffe & Data Augmentation \\
\hline
\end{tabular}


B Summarization

Table 4: Diseases and their Pathogens grouped by Dataset and Studies

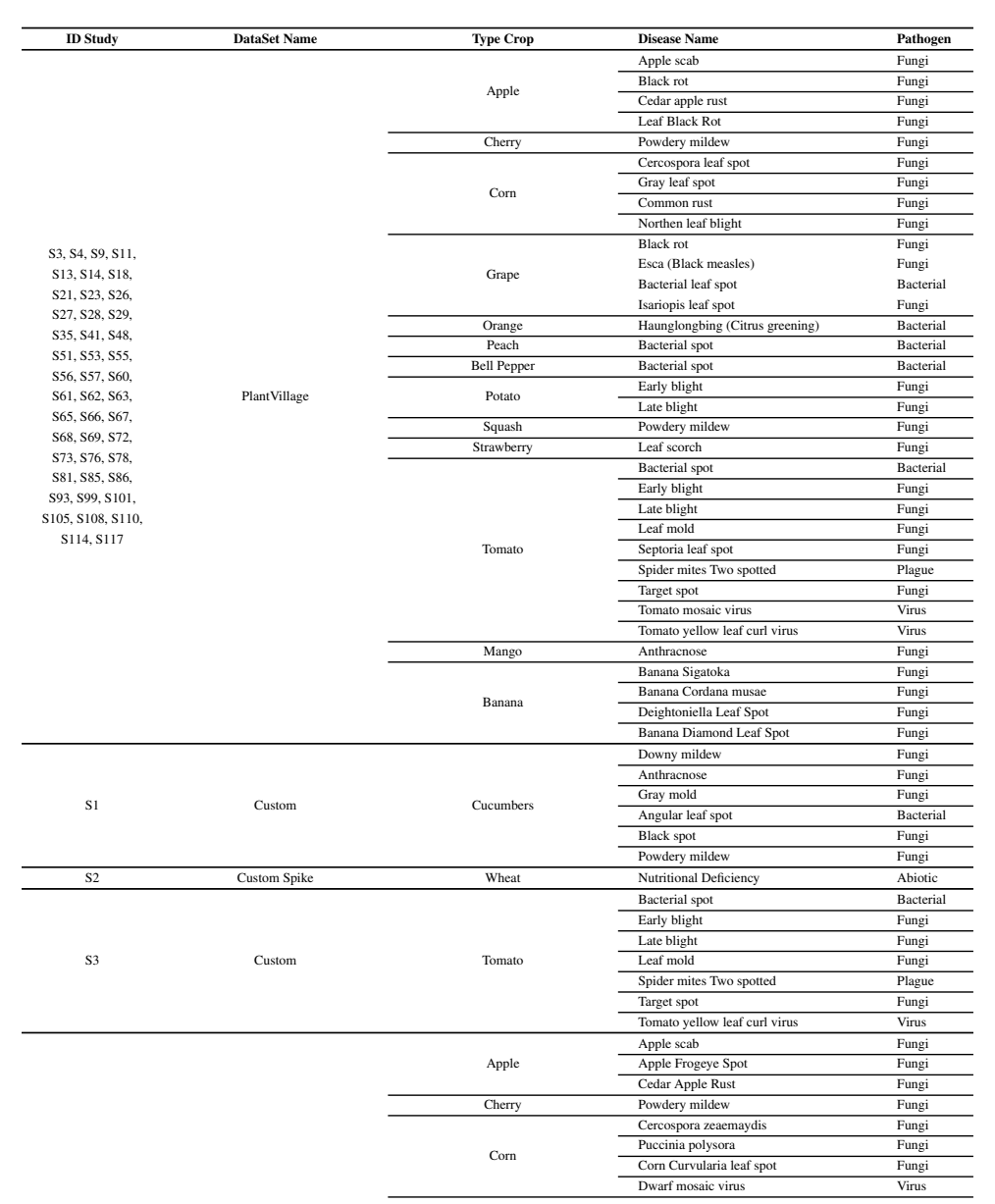




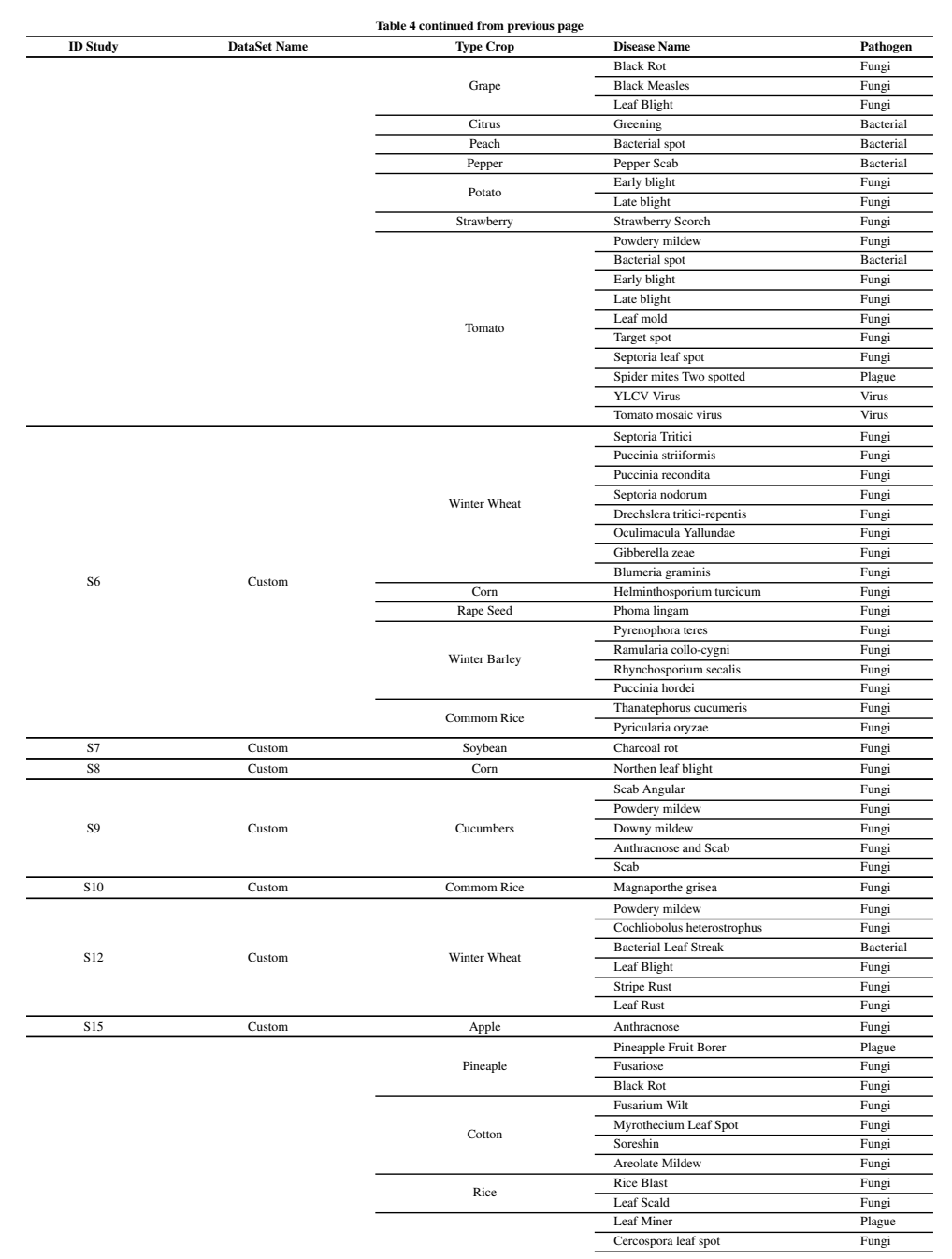

Coffe 


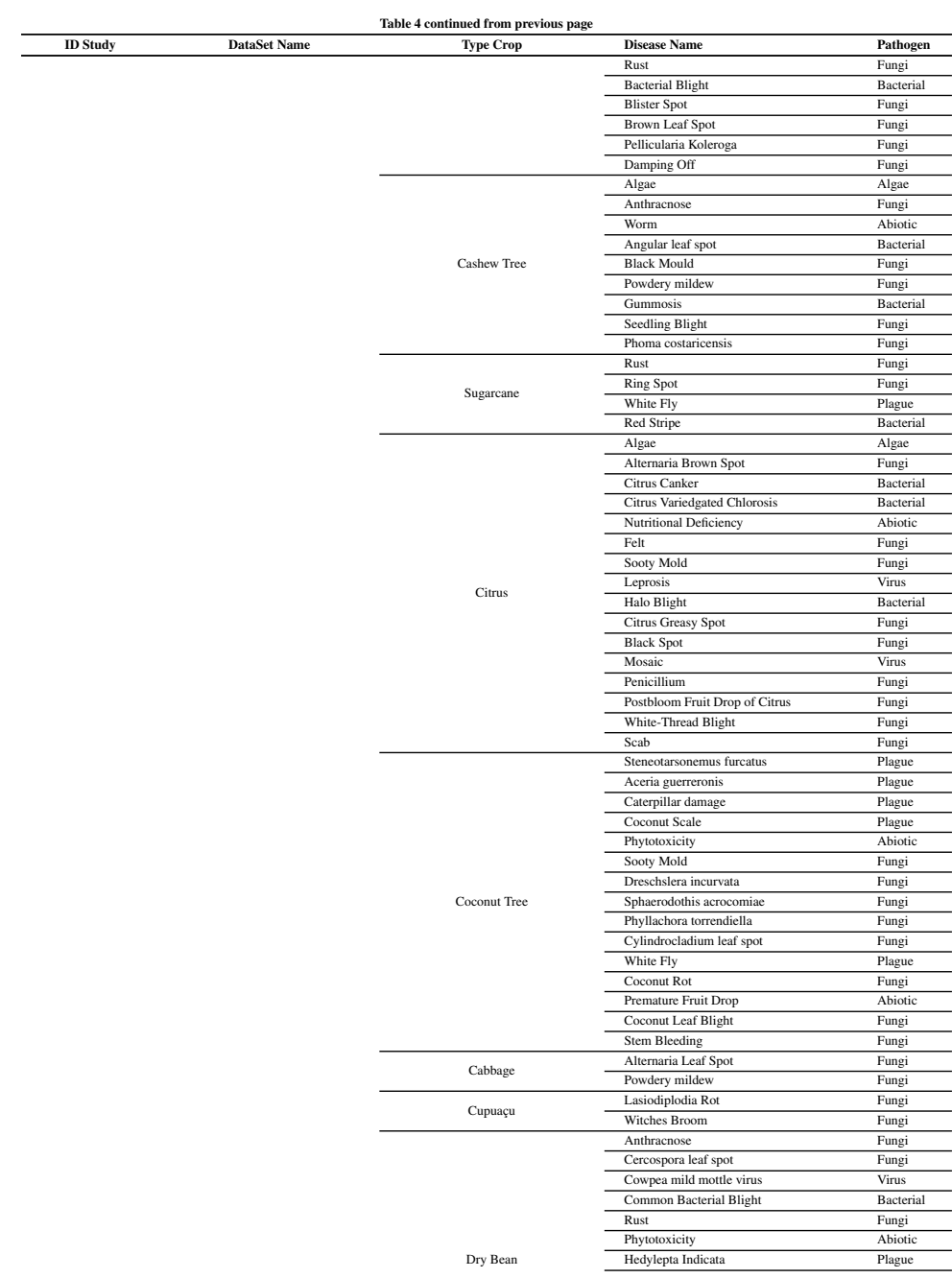




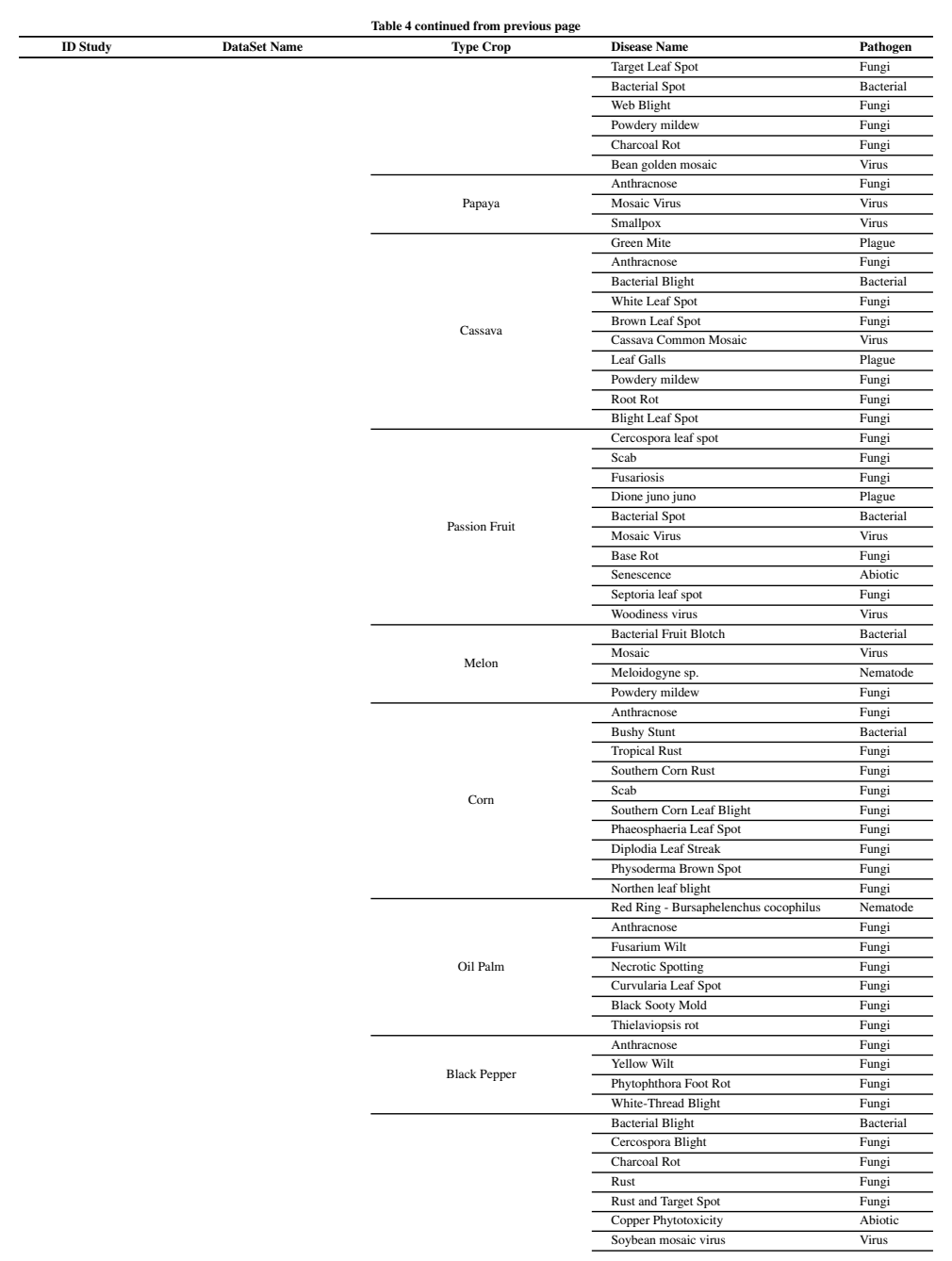




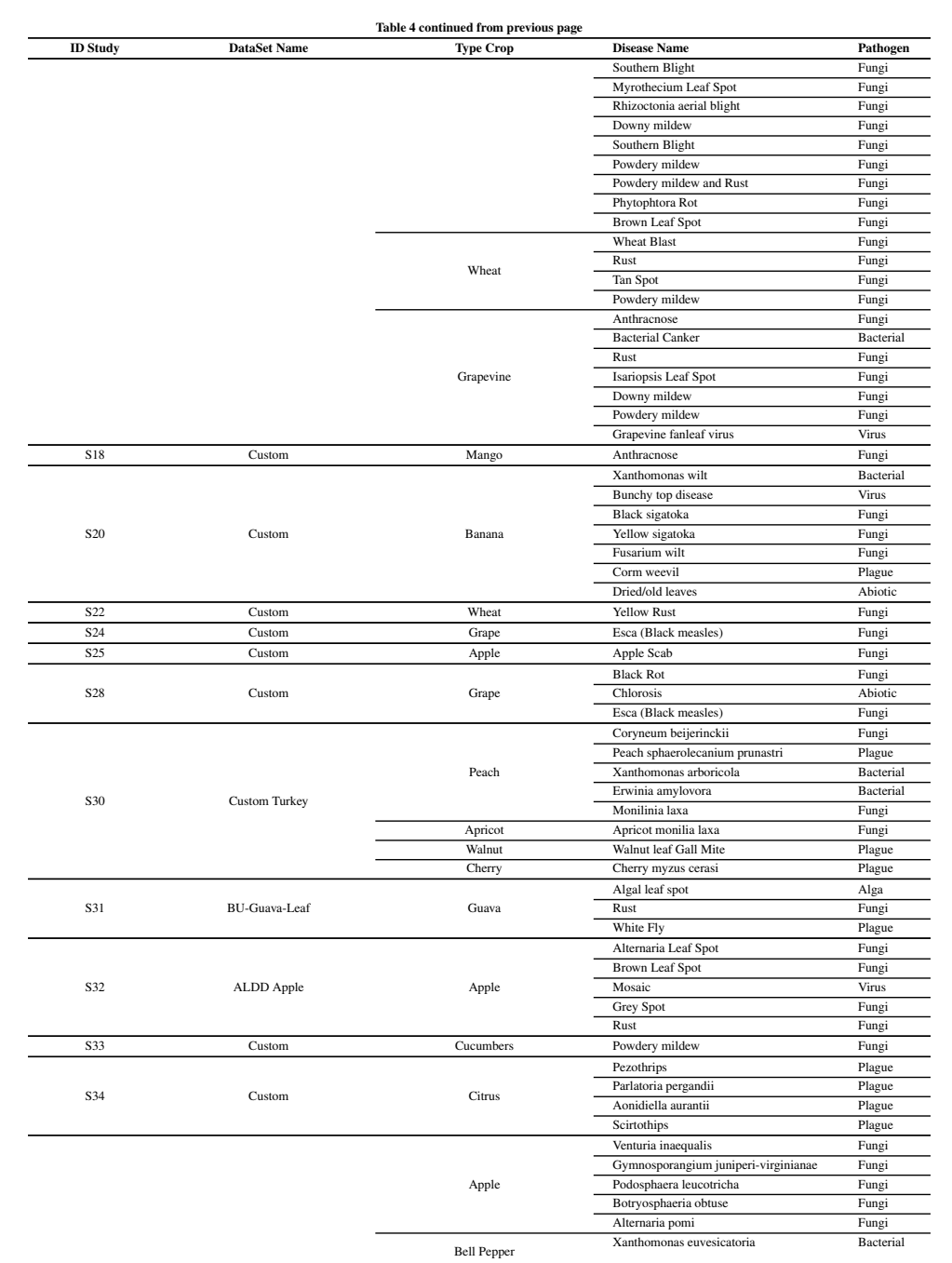




\begin{tabular}{|c|c|c|c|c|}
\hline \multicolumn{5}{|c|}{ Table 4 continued from pre } \\
\hline Wouag & Dataset Name & $\begin{aligned} \text { lype Crop } \\
\end{aligned}$ & $\begin{array}{l}\text { Disease Name } \\
\text { Xanthomonas campestris }\end{array}$ & $\begin{array}{c}\text { Pathogen } \\
\text { Bacterial }\end{array}$ \\
\hline & & cherry & $\begin{array}{l}\text { Blumerichla jappii } \\
\text { Popdosphatr spp. }\end{array}$ & $\begin{array}{c}\text { Fungi } \\
\text { Fungi }\end{array}$ \\
\hline & & & 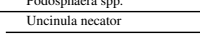 & \\
\hline & & & $\begin{array}{l}\text { Plasmopiara viticola } \\
\text { Botryyis incrall }\end{array}$ & $\begin{array}{ll}\text { Fungi } \\
\text { Fungi }\end{array}$ \\
\hline & & Grape & Botryosphaneria bbtuse & Fungi \\
\hline & & & 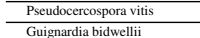 & $\begin{array}{l}\text { Fungi } \\
\text { Fungi }\end{array}$ \\
\hline & & & & \\
\hline & & Onion & \begin{tabular}{|l|l|} 
Peronospora destructor \\
\end{tabular} & Fungi \\
\hline & & $\begin{array}{l}\text { Peach } \\
\text { Patato }\end{array}$ & $\begin{array}{l}\text { Clasterosporium carpophilum } \\
\text { Alteraria solani }\end{array}$ & $\begin{array}{l}\text { Fungi } \\
\text { Fumpoi }\end{array}$ \\
\hline & & & 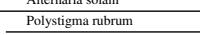 & $\begin{array}{l}\text { Fungi } \\
\text { Fungi }\end{array}$ \\
\hline & & Plum & $\begin{array}{l}\text { Plum Plox } \\
\text { Tranzchelia pruni-spinosace }\end{array}$ & $\begin{array}{lll}\text { Virus } \\
\text { Fumpi }\end{array}$ \\
\hline & & & $\begin{array}{l}\text { Trannschelila prunlinspinosace } \\
\text { Sigmmina carpoflia }\end{array}$ & $\begin{array}{l}\text { Fungi } \\
\text { Fungi }\end{array}$ \\
\hline & & Strawberry & 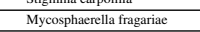 & Funge \\
\hline & & Sugar beets & Cercosporaran beticicola & $\begin{array}{ll}\text { Fust } \\
\text { Fungi }\end{array}$ \\
\hline & & $\begin{array}{c}\text { Tomato } \\
\end{array}$ & 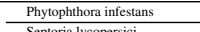 & Fungi \\
\hline & & & \begin{tabular}{|l|} 
Septorialycoporesici \\
Erysiphe graminis
\end{tabular} & Fungi \\
\hline & & Wheat & Poctinia spe. & \\
\hline & & & Septoria spp. & Fungi \\
\hline 536 & Custom & Millet & Mildew & Fungi \\
\hline $\begin{array}{c}537 \\
\end{array}$ & Custom & Potato & Potato PVY & \\
\hline $\mathrm{m}^{-1}$ & & & Tea bud blight & Fungi \\
\hline S38 & Custom & Tea Laf & 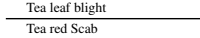 & $\begin{array}{l}\text { Fungi } \\
\text { Fungi }\end{array}$ \\
\hline s39 & Custom & Apple & Marssonia Blotch & Fungi \\
\hline & & & $\begin{array}{l}\text { Alternaraiacear Spot } \\
\text { Brown strcek }\end{array}$ & $\begin{array}{l}\text { Fungi } \\
\text { Virus } \\
\text { nats }\end{array}$ \\
\hline & & & Mosaic & Vius \\
\hline s40 & IITA Cassava & Cassava & $\begin{array}{l}\text { Green Mite } \\
\text { Ped Mire }\end{array}$ & $\begin{array}{ll}\text { Plague } \\
\text { poger }\end{array}$ \\
\hline & & & $\begin{array}{l}\text { Red dite } \\
\text { Brown Leaf Spot }\end{array}$ & $\begin{array}{l}\text { lagauc } \\
\text { Fungi }\end{array}$ \\
\hline & & & $\begin{array}{l}\text { Nutritional Defficiency } \\
\text { Northen laf flight }\end{array}$ & $\begin{array}{l}\text { Abiouic } \\
\text { Fungi }\end{array}$ \\
\hline$\$ 43$ & Custom & Corn & Puccinia Sorghi & $\begin{array}{l}\text { Thagt } \\
\text { Fungi } \\
\end{array}$ \\
\hline & & & Gray Leaf Spot & Fungi \\
\hline & & & $\begin{array}{c}\text { Malformed frut } \\
\text { Blochy ripening }\end{array}$ & $\begin{array}{l}\text { Abaiotic } \\
\text { Abiotic }\end{array}$ \\
\hline & & & Puffy fruit & Abiotic \\
\hline & & & $\begin{array}{l}\text { Dehissent fruit } \\
\text { Blossom-end rot }\end{array}$ & $\begin{array}{l}\text { Abioitic } \\
\text { Abioic }\end{array}$ \\
\hline (3t & Custom & Tomato & $\begin{array}{l}\text { Sunscald } \\
\end{array}$ & Abiotic \\
\hline & & & $\begin{array}{ll}\text { Tomato Virus } \\
\text { S }\end{array}$ & Virus \\
\hline & & & $\begin{array}{l}\text { Oryaninuce } \\
\text { Tomato ulcer } \\
\end{array}$ & $\begin{array}{l}\text { Fugni } \\
\text { Fungi }\end{array}$ \\
\hline s45 & Custom & Sugar beets & \begin{tabular}{|l|} 
Altrachose \\
Cercospora Leaf Spot
\end{tabular} & $\begin{array}{l}\text { Fungi } \\
\text { Fungi } \\
\end{array}$ \\
\hline & & & Whitc Laaf Spot & \\
\hline & & & $\begin{array}{l}\text { Birds eye spot } \\
\end{array}$ & Fungi \\
\hline s46 & Custom & Tea Leaf & $\begin{array}{l}\text { Red deac f spot } \\
\text { Gray bight }\end{array}$ & $\begin{array}{ll}\text { Allag } \\
\text { Fungi }\end{array}$ \\
\hline & & & $\begin{array}{l}\text { Anthraconse } \\
\text { Brown Blieht }\end{array}$ & $\begin{array}{ll}\text { Fungi } \\
\text { Bactrial }\end{array}$ \\
\hline & & & Alalal leat pot & \\
\hline 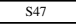 & Custom & Com & Northen leaf bigight & Fungi \\
\hline S49 & Custom & $\begin{array}{l}\text { Cirus } \\
\end{array}$ & Citrus Canker & Bacterial \\
\hline
\end{tabular}




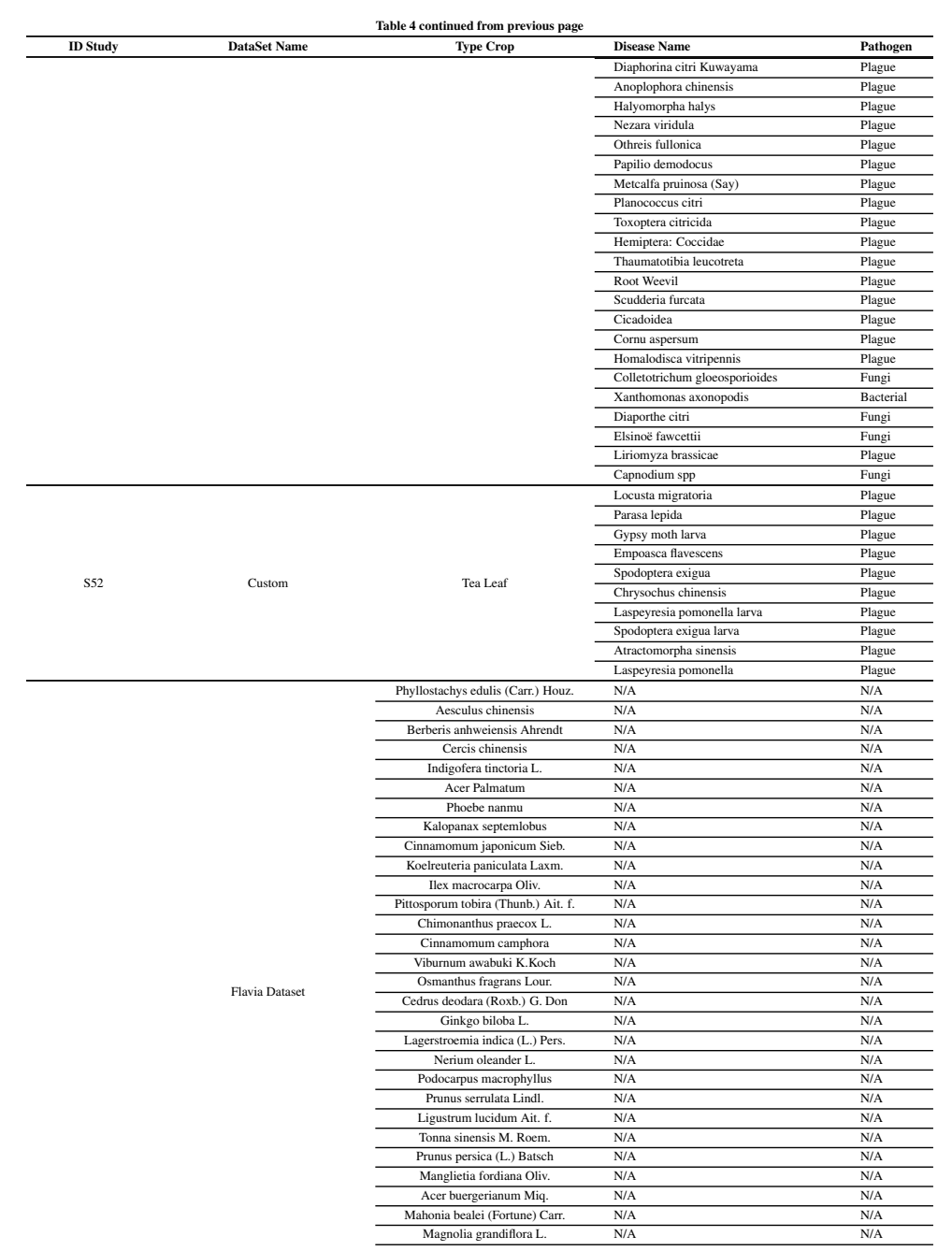




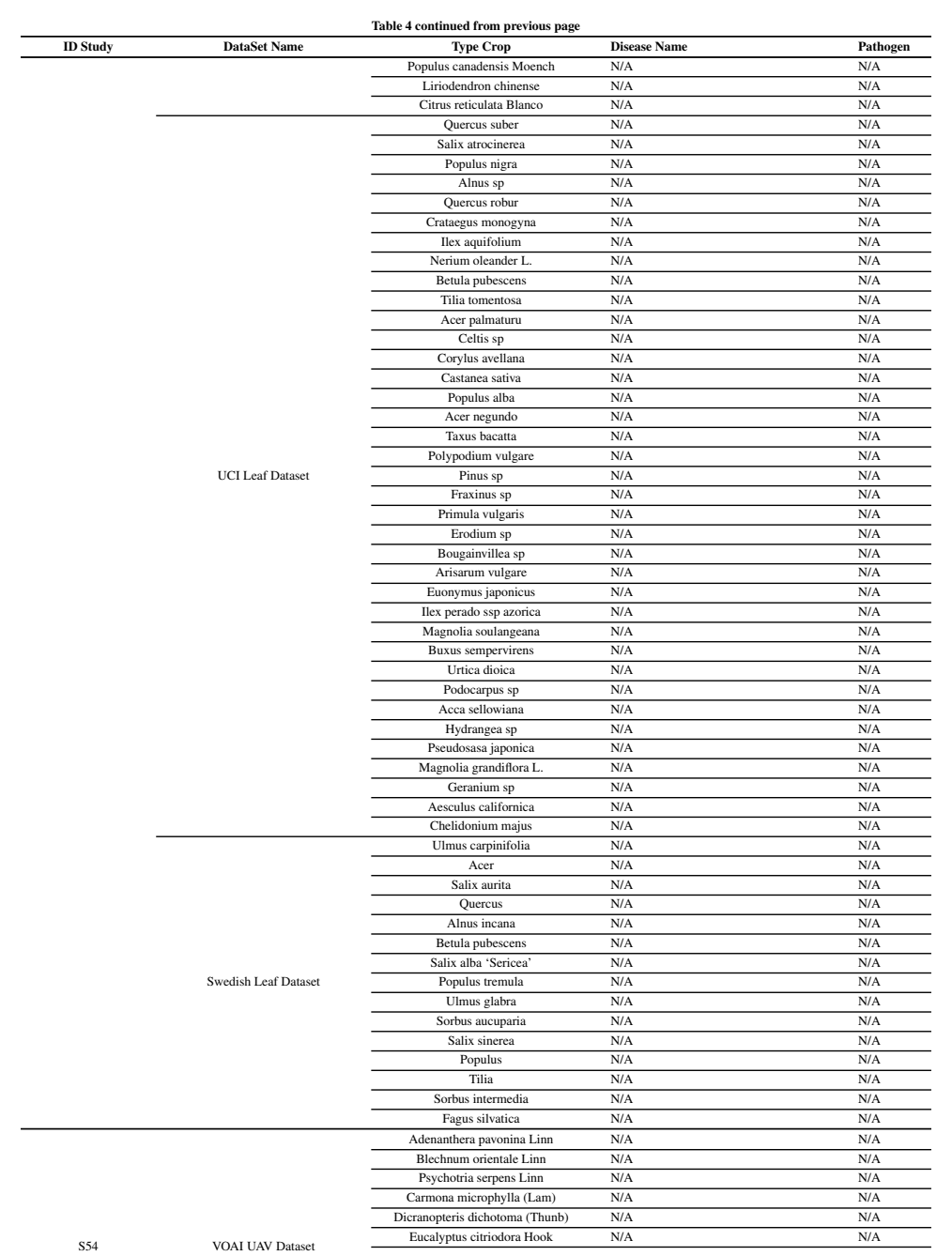




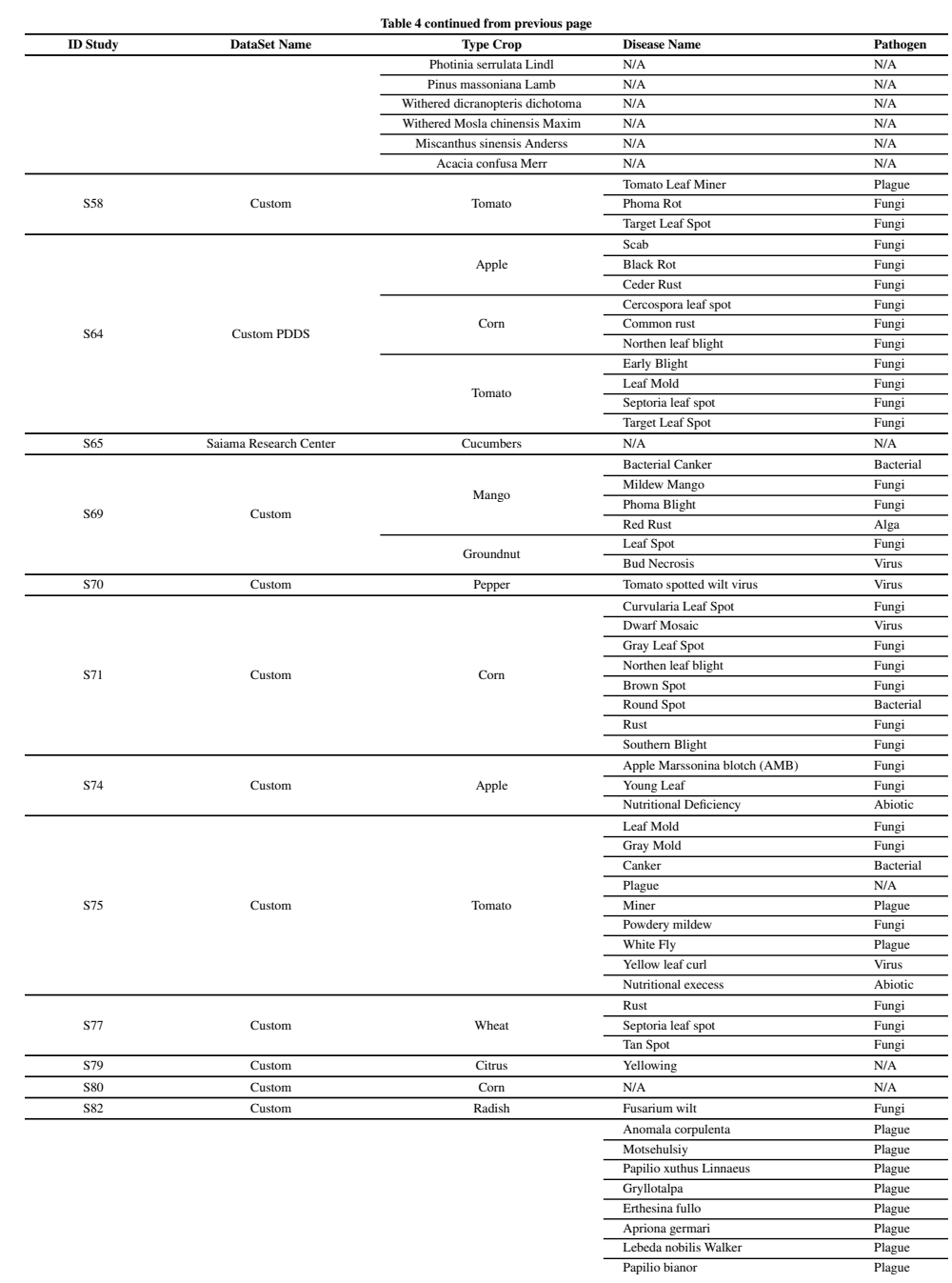

S83 Pest mage Datasset N/A




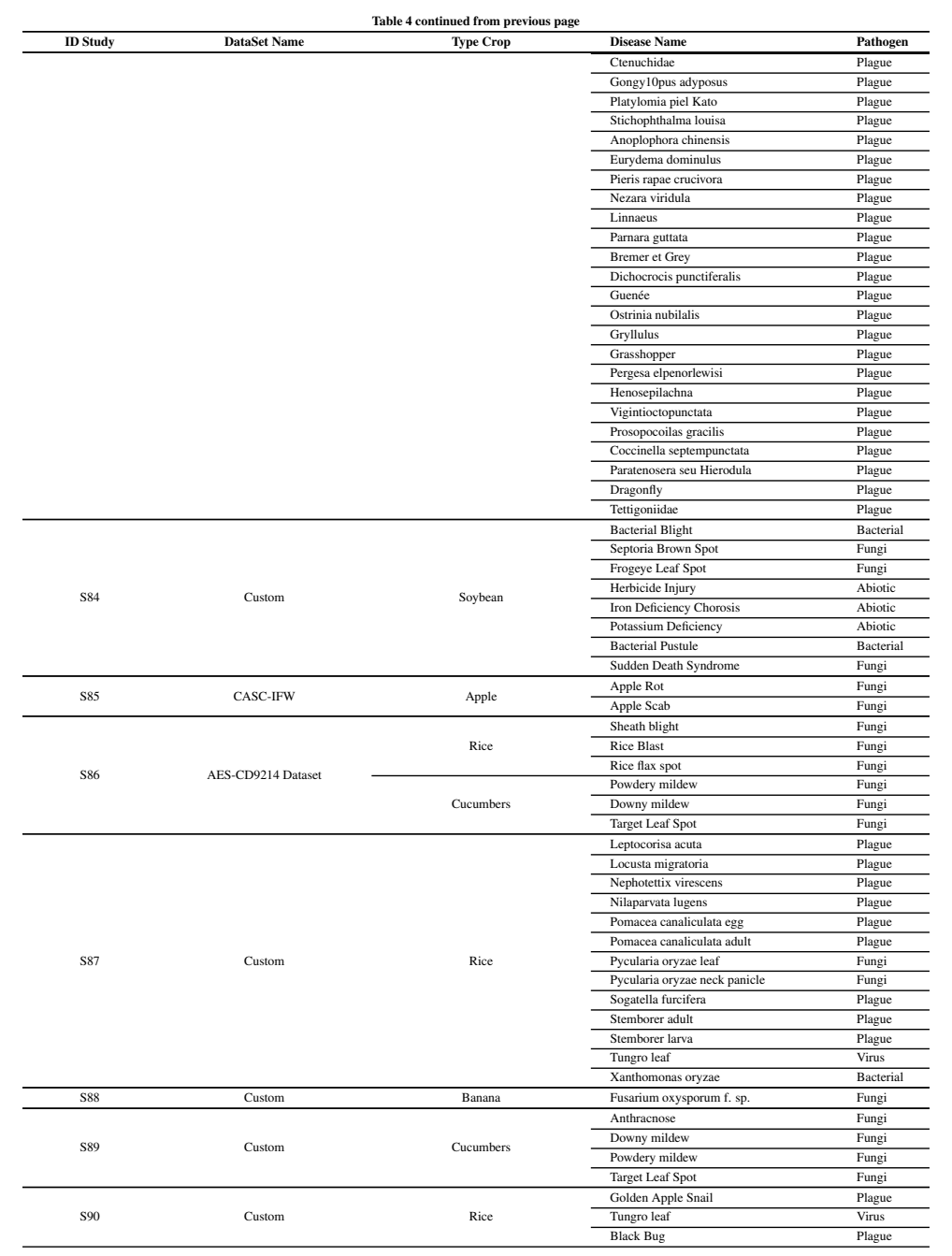




\begin{tabular}{|c|c|c|c|c|}
\hline ID Study & $\begin{array}{l}\text { DataSet Name } \\
\end{array}$ & Type Crop & $\begin{array}{l}\text { Disease Name } \\
\end{array}$ & Pathogen \\
\hline \multirow{6}{*}{ s91 } & \multirow{6}{*}{ Custom } & \multirow{7}{*}{ Rice } & $\begin{array}{c}\text { Bacterial Leaf Blight } \\
\text { Brown Spot }\end{array}$ & $\begin{array}{l}\text { Bacterial } \\
\text { Ffumi }\end{array}$ \\
\hline & & & Brown spout Hopper & \\
\hline & & & $\begin{array}{l}\text { False smut } \\
\end{array}$ & Fungi \\
\hline & & & $\frac{\text { Stemborer adult }}{\text { Hispa }}$ & $\begin{array}{l}\text { Playe } \\
\text { Plague }\end{array}$ \\
\hline & & & Neck Blast & \\
\hline & & & $\begin{array}{l}\text { Sheath Blight } \\
\text { Sheos Bo }\end{array}$ & \\
\hline \multirow{3}{*}{592} & \multirow{3}{*}{ Custom } & & $\begin{array}{ll}\text { Sheach Sor } \\
\text { Blak Scurf }\end{array}$ & Fungi \\
\hline & & \multirow{2}{*}{ Potato } & Silver S Surf & Fungi \\
\hline & & & $\begin{array}{l}\text { Common ncab } \\
\text { Black Dot }\end{array}$ & $\begin{array}{l}\text { Bacterial } \\
\text { Fungi }\end{array}$ \\
\hline \multirow{2}{*}{ s94 } & \multirow{2}{*}{ TRES Taivan Tea Research } & \multirow{2}{*}{ Tea Leaf } & Brown Blight & Bacterial \\
\hline & & & $\begin{array}{l}\text { Bisiser light } \\
\text { Algat leaf spot }\end{array}$ & $\begin{array}{ll}\text { Fungi } \\
\text { Allga }\end{array}$ \\
\hline 595 & Custom UAV & Rice & & \\
\hline \multirow{3}{*}{ s96 } & \multirow{3}{*}{ Custom } & \multirow{3}{*}{ Com } & $\begin{array}{l}\text { Com Laaf spot } \\
\text { Smal St Sot }\end{array}$ & $\begin{array}{ll}\text { Fungi } \\
\text { Fungi }\end{array}$ \\
\hline & & & $\begin{array}{l}\text { Sman Spol } \\
\text { Leaf Spot } \\
\end{array}$ & $\begin{array}{ll}\text { Fugh } \\
\text { Fungi }\end{array}$ \\
\hline & & & $\begin{array}{l}\text { Brown Spot } \\
\text { Straka and round spot }\end{array}$ & $\begin{array}{ll}\text { Fungi } \\
\text { Virus }\end{array}$ \\
\hline 597 & Custom & Grape & $\begin{array}{l}\text { Sorcak and ounuspot } \\
\text { Esca (Black measles) }\end{array}$ & $\begin{array}{l}\text { Finus } \\
\text { Fungi } \\
\end{array}$ \\
\hline \multirow{6}{*}{ s98 } & \multirow{6}{*}{ Custom } & \multirow{6}{*}{ Cucumbers } & Melon yellow spot virus & Virus \\
\hline & & & 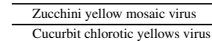 & $\begin{array}{ll}\text { Virus } \\
\text { Virus } \\
\end{array}$ \\
\hline & & & Cucumber mosaic virus & Virus \\
\hline & & & 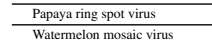 & $\begin{array}{lll}\text { Virus } \\
\text { Virum }\end{array}$ \\
\hline & & & $\begin{array}{c}\text { Green mottle mosaic Virus } \\
\end{array}$ & \\
\hline & & & $\begin{array}{c}\text { Downy mildew } \\
\text { bagctian wilt }\end{array}$ & $\begin{array}{l}\text { Fungi } \\
\text { Bactrial }\end{array}$ \\
\hline \multirow{7}{*}{$\$ 100$} & \multirow{7}{*}{ Custom } & \multirow{7}{*}{ Rice } & $\begin{array}{l}\text { bacecan wit } \\
\text { secding blight } \\
\end{array}$ & $\begin{array}{l}\text { Baceral } \\
\text { Fungi }\end{array}$ \\
\hline & & & 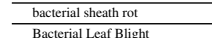 & $\begin{array}{l}\text { Bacterial } \\
\text { Batcrial } \\
\end{array}$ \\
\hline & & & Sheath Rot & Fungi \\
\hline & & & 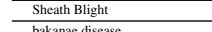 & $\begin{array}{ll}\text { Fungi } \\
\text { Fupging }\end{array}$ \\
\hline & & & 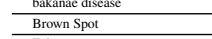 & $\begin{array}{l}\text { Fungl } \\
\text { Fungi }\end{array}$ \\
\hline & & & $\begin{array}{ll}\text { False smut } \\
\text { ale sut }\end{array}$ & Fungi \\
\hline & & & & \\
\hline \multirow{5}{*}{$\$ 102$} & \multirow{5}{*}{ Custom } & \multirow{5}{*}{ Tomato } & $\begin{array}{l}\text { Nurutitonal excess } \\
\text { Whiteny }\end{array}$ & $\begin{array}{l}\text { A Aloitic } \\
\text { Plague }\end{array}$ \\
\hline & & & 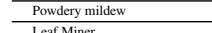 & Fungi \\
\hline & & & Leaf Miner & 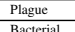 \\
\hline & & & Garay mold & \\
\hline & & & & \\
\hline 5103 & Custom & Maize & Northem leaf bight (NLB-B & Fungi \\
\hline \multirow{3}{*}{ s104 } & \multirow{3}{*}{ Custom } & \multirow{3}{*}{ Strawberry } & Gray mold rot & Fungi \\
\hline & & & $\begin{array}{l}\text { Powdery mildew } \\
\text { Fusarium will }\end{array}$ & $\begin{array}{l}\text { Fungi } \\
\text { Fungi }\end{array}$ \\
\hline & & & 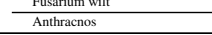 & $\begin{array}{l}\text { Fugh } \\
\text { Fungi }\end{array}$ \\
\hline & & & $\begin{array}{l}\text { Cassava mosaic discase } \\
\text { Cassava brown strake dicesesc }\end{array}$ & \\
\hline s106 & Custom & Casava & $\begin{array}{c}\text { Cassava brown strcak disease } \\
\text { Griecn mite damagc }\end{array}$ & $\begin{array}{l}\text { Virus } \\
\text { Playere }\end{array}$ \\
\hline & & & Red mite damage & $\begin{array}{ll}P \text { Pagave } \\
\text { Plague }\end{array}$ \\
\hline 8107 & Custom & Apple & $\begin{array}{l}\text { Brown leaf spot } \\
\text { Athioic disturth }\end{array}$ & Fungi \\
\hline & European Wood & Diverese & & \\
\hline & & isce & N/A & N/A \\
\hline
\end{tabular}




\begin{tabular}{|c|c|c|c|c|}
\hline ID Study & DataSet Name & Type Crop & Disease Name & Pathogen \\
\hline & Foliage Leaf Dataset & Diverse & N/A & \\
\hline & & Diverse & $\mathrm{N} / \mathrm{A}$ & \\
\hline$\frac{S 111}{S 12}$ & Bjificioximaia & Fowers & $\mathrm{N} / \mathrm{A}$ & N/A \\
\hline \multirow{3}{*}{5113} & \multirow{3}{*}{ Custom } & Radish & $\begin{array}{l}\text { Fosarium will of radish } \\
\text { Mosiac }\end{array}$ & $\begin{array}{l}\text { Fungi } \\
\text { Virus } \\
\end{array}$ \\
\hline & & \multirow{2}{*}{ Apple } & $\begin{array}{ll}\text { Brown spot } \\
\text { Bew spen }\end{array}$ & Fungi \\
\hline & & & $\begin{array}{l}\text { Rust } \\
\text { Alternaria leaf spot } \\
\end{array}$ & $\begin{array}{l}\text { Fungi } \\
\text { Fungi }\end{array}$ \\
\hline \multirow{11}{*}{ S115 } & \multirow{11}{*}{ Custom } & \multirow{2}{*}{$\begin{array}{l}\text { Pear } \\
\text { Cherrv }\end{array}$} & $\begin{array}{l}\text { Porosity } \\
\text { Evrinia anylovora } \\
\end{array}$ & $\begin{array}{ll}\mathrm{NA} \\
\text { Bacterial }\end{array}$ \\
\hline & & & $\begin{array}{ll}\text { Venturia } \\
\text { ponvers }\end{array}$ & $\begin{array}{l}\text { Fungi } \\
\text { ug }\end{array}$ \\
\hline & & Cherry & $\begin{array}{ll}\text { Porosity } \\
\text { Prosity }\end{array}$ & \\
\hline & & \multirow[t]{2}{*}{ Peach } & 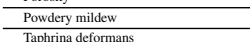 & Fungi \\
\hline & & & Erwinia amylovora & \\
\hline & & \multirow[t]{2}{*}{ Apple } & 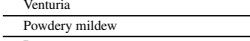 & Fungi \\
\hline & & & & \\
\hline & & Pair & 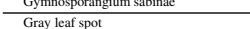 & 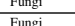 \\
\hline & & \multirow{3}{*}{ Grapevine } & Wilt & Fungi \\
\hline & & & & $\begin{array}{cl}P \text { Plague } \\
\text { Pagu }\end{array}$ \\
\hline & & & $\begin{array}{l}\text { Powdery mildew } \\
\text { Downy mildew }\end{array}$ & Fungi \\
\hline \multirow{3}{*}{$\$ 116$} & \multirow{3}{*}{ Custom } & \multirow{3}{*}{ Apple } & Scab skin & Fungi \\
\hline & & & $\begin{array}{l}\text { Black rot } \\
\text { B. }\end{array}$ & $\begin{array}{l}\text { Fungi } \\
\end{array}$ \\
\hline & & & $\begin{array}{l}\text { Sara skinin } \\
\text { Rer }\end{array}$ & \\
\hline \multirow{4}{*}{ s118 } & \multirow{4}{*}{ Custom } & \multirow{4}{*}{ Apple } & $\begin{array}{l}\text { Kngs spon } \\
\text { Potassium defficiency }\end{array}$ & Abiotic \\
\hline & & & $\begin{array}{l}\text { Magnesium defficiency } \\
\end{array}$ & $\frac{\mathrm{NA}}{\mathrm{Na}}$ \\
\hline & & & $\begin{array}{l}\text { Scab damage } \\
\text { Gilomerchlatsin } \\
\end{array}$ & Fungi \\
\hline & & & Heribicide samage & NAg \\
\hline \multirow{4}{*}{ s119 } & \multirow{4}{*}{ Custom } & \multirow{4}{*}{ Cucumbers } & $\begin{array}{l}\text { Melon yellow spot virus: MYSV } \\
\text { Zucchini yellew mosaic virus: ZYMVV }\end{array}$ & $\begin{array}{l}\text { Virus } \\
\text { Virus } \\
\end{array}$ \\
\hline & & & $\begin{array}{l}\text { Cucurbit clorotic yellows virus: } \mathrm{CCYV} \\
\end{array}$ & Virus \\
\hline & & & $\begin{array}{l}\text { Cucumber mosiaic virus: CMV } \\
\text { Paraya aning spot virus PRSV }\end{array}$ & $\begin{array}{l}\text { Virus } \\
\text { Virus } \\
\text { S }\end{array}$ \\
\hline & & & $\begin{array}{l}\text { Watemmelon mosaic virus: WMV } \\
\text { Giveres }\end{array}$ & $\begin{array}{l}\text { Virus } \\
\end{array}$ \\
\hline$s 121$ & Custom & Cumcumber & Melon yellow spot virus: MYSV & $\frac{V_{i n s}}{\text { Viris }}$ \\
\hline & & & & \\
\hline
\end{tabular}

Andre S. Abade and Flávio de Barros Vidal (University of Brasília, Brasília, Brazil and Paulo Afonso Ferreira (Department of Agronomy, Federal University of Mato Grosso, Brazil)

E-mail: fbvidal@unb.br 


\section{References}

[1] M. Altieri. Agroecology: The Science Of Sustainable Agriculture. CRC Press, Endereço, 2nd edition edition, February 2018.

[2] Sharada P. Mohanty, David P. Hughes, and Marcel Salathé. Using deep learning for image-based plant disease detection. Frontiers in Plant Science, 7:1419, 2016.

[3] Sally A. Miller, Fen D. Beed, and Carrie Lapaire Harmon. Plant Disease Diagnostic Capabilities and Networks. Annual Review of Phytopathology, 47(1):15-38, sep 2009.

[4] Anne-Katrin Mahlein. Plant disease detection by imaging sensors - parallels and specific demands for precision agriculture and plant phenotyping. Plant Disease, 100(2):241-251, 2016.

[5] Jayme Garcia Arnal Barbedo. Digital image processing techniques for detecting, quantifying and classifying plant diseases. SpringerPlus, 2(1):660, Dec 2013.

[6] Y. Lecun, L. Bottou, Y. Bengio, and P. Haffner. Gradient-based learning applied to document recognition. Proceedings of the IEEE, 86(11):2278-2324, Nov 1998.

[7] Sindhuja Sankaran, Ashish Mishra, Reza Ehsani, and Cristina Davis. A review of advanced techniques for detecting plant diseases. Computers and Electronics in Agriculture, 72(1):1 - 13, 2010.

[8] Federico Martinelli, Riccardo Scalenghe, Salvatore Davino, Stefano Panno, Giuseppe Scuderi, Paolo Ruisi, Paolo Villa, Daniela Stroppiana, Mirco Boschetti, Luiz R. Goulart, Cristina E. Davis, and Abhaya M. Dandekar. Advanced methods of plant disease detection. a review. Agronomy for Sustainable Development, 35(1):1-25, Jan 2015.

[9] Y. Lecun, L. Bottou, Y. Bengio, and P. Haffner. Gradient-based learning applied to document recognition. Proceedings of the IEEE, 86(11):2278-2324, Nov 1998.

[10] Alex Krizhevsky, Ilya Sutskever, and Geoffrey E. Hinton. Imagenet classification with deep convolutional neural networks. In Proceedings of the 25th International Conference on Neural Information Processing Systems - Volume 1, NIPS'12, pages 1097-1105, USA, 2012. Curran Associates Inc.

[11] Karen Simonyan and Andrew Zisserman. Very deep convolutional networks for large-scale image recognition. CoRR, abs/1409.1556, 2014.

[12] C. Szegedy, Wei Liu, Yangqing Jia, P. Sermanet, S. Reed, D. Anguelov, D. Erhan, V. Vanhoucke, and A. Rabinovich. Going deeper with convolutions. In 2015 IEEE Conference on Computer Vision and Pattern Recognition (CVPR), pages 1-9, June 2015.

[13] Christian Szegedy, Vincent Vanhoucke, Sergey Ioffe, Jonathon Shlens, and Zbigniew Wojna. Rethinking the inception architecture for computer vision. 2016 IEEE Conference on Computer Vision and Pattern Recognition (CVPR), pages 2818-2826, 2015. 
[14] K. He, X. Zhang, S. Ren, and J. Sun. Deep residual learning for image recognition. In 2016 IEEE Conference on Computer Vision and Pattern Recognition (CVPR), pages 770-778, June 2016.

[15] G. Huang, Z. Liu, L. v. d. Maaten, and K. Q. Weinberger. Densely connected convolutional networks. In 2017 IEEE Conference on Computer Vision and Pattern Recognition (CVPR), pages 2261-2269, July 2017.

[16] Barbara Kitchenham. Procedures for performing systematic reviews. Keele university. technical report tr/se-0401, Keele University Technical Report, Department of Computer Science, Keele University, UK, 2004.

[17] Sandra C. P. F. Fabbri, Katia R. Felizardo, Fabiano Cutigi Ferrari, E. C. M. Hernandes, F. R. Octaviano, E. Y. Nakagawa, and J. C. Maldonado. Externalising tacit knowledge of the systematic review process. IET Software, 7(6):298-307, 2013.

[18] Jayme Garcia Arnal Barbedo. A review on the main challenges in automatic plant disease identification based on visible range images. Biosystems Engineering, 144:52 - 60, 2016.

[19] Z. B. Husin, A. Y. B. M. Shakaff, A. H. B. A. Aziz, and R. B. S. M. Farook. Feasibility study on plant chili disease detection using image processing techniques. In 2012 Third International Conference on Intelligent Systems Modelling and Simulation, pages 291-296, Feb 2012.

[20] George Agrios. Plant pathology: Fifth edition, volume 9780080473789. Academic Press, dec 2005.

[21] Ian Goodfellow, Yoshua Bengio, and Aaron Courville. Deep Learning. MIT Press, 2016. http://www.deeplearningbook. org.

[22] Asifullah Khan, Anabia Sohail, Umme Zahoora, and Aqsa Saeed Qureshi. A survey of the recent architectures of deep convolutional neural networks. CoRR, abs/1901.06032, 2019.

[23] S. J. Pan and Q. Yang. A survey on transfer learning. IEEE Transactions on Knowledge and Data Engineering, 22(10):13451359 , Oct 2010.

[24] L. Shao, F. Zhu, and X. Li. Transfer learning for visual categorization: A survey. IEEE Transactions on Neural Networks and Learning Systems, 26(5):1019-1034, May 2015.

[25] Ines Khandelwal and Sundaresan Raman. Analysis of transfer and residual learning for detecting plant diseases using images of leaves. In Nishchal K. Verma and A. K. Ghosh, editors, Computational Intelligence: Theories, Applications and Future Directions - Volume II, pages 295-306, Singapore, 2019. Springer Singapore.

[26] T. Sledevic. Adaptation of convolution and batch normalization layer for cnn implementation on fpga. In 2019 Open Conference of Electrical, Electronic and Information Sciences (eStream), pages 1-4, 2019.

[27] Connor Shorten and Taghi M. Khoshgoftaar. A survey on image data augmentation for deep learning. Journal of Big Data, 6(1):60, Jul 2019. 
[28] Elis Montoro Hernandes, Augusto Zamboni, Sandra Fabbri, and A. Di Thommazo. Using GQM and TAM to evaluate StArt - a tool that supports systematic review. CLEI Electronic Journal, 15(1), 2012.

[29] Kai Petersen, Robert Feldt, Shahid Mujtaba, and Michael Mattsson. Systematic mapping studies in software engineering. In 12th International Conference on Evaluation and Assessment in Software Engineering (EASE), pages 68-77, Swinton, UK, UK, 2008. British Computer Society.

[30] Barbara A. Kitchenham. Systematic review in software engineering: Where we are and where we should be going. In Proceedings of the 2Nd International Workshop on Evidential Assessment of Software Technologies, EAST '12, pages 1-2, New York, NY, USA, 2012. ACM

[31] Mark Staples and Mahmood Niazi. Experiences using systematic review guidelines. J. Syst. Softw., 80(9):1425-1437, September 2007.

[32] Alessandro Liberati, Douglas G. Altman, Jennifer Tetzlaff, Cynthia Mulrow, Peter C. Gøtzsche, John P.A. Ioannidis, Mike Clarke, P. J. Devereaux, Jos Kleijnen, and David Moher. The PRISMA Statement for Reporting Systematic Reviews and Meta-Analyses of Studies That Evaluate Health Care Interventions: Explanation and Elaboration. Annals of Internal Medicine, 151(4):W-65-W-94, 082009.

[33] Nina Buscemi, Lisa Hartling, Ben Vandermeer, Lisa Tjosvold, and Terry P. Klassen. Single data extraction generated more errors than double data extraction in systematic reviews. Journal of Clinical Epidemiology, 59(7):697-703, jul 2006.

[34] David P. Hughes and Marcel Salathé. An open access repository of images on plant health to enable the development of mobile disease diagnostics through machine learning and crowdsourcing. CoRR, abs/1511.08060, 2016.

[35] Sambuddha Ghosal, David Blystone, Asheesh K. Singh, Baskar Ganapathysubramanian, Arti Singh, and Soumik Sarkar. An explainable deep machine vision framework for plant stress phenotyping. Proceedings of the National Academy of Sciences, 115(18):4613-4618, 2018.

[36] Bin Liu, Yun Zhang, DongJian He, and Yuxiang Li. Identification of apple leaf diseases based on deep convolutional neural networks. Symmetry, 10(1), 2017.

[37] Weihui Zeng, Miao Li, Jian Zhang, Lei Chen, Sisi Fang, and Jingxian Wang. High-order residual convolutional neural network for robust crop disease recognition. In Proceedings of the 2Nd International Conference on Computer Science and Application Engineering, CSAE '18, pages 101:1-101:5, New York, NY, USA, 2018. ACM.

[38] Yunong Tian, Guodong Yang, Zhe Wang, En Li, and Zize Liang. Detection of apple lesions in orchards based on deep learning methods of cyclegan and yolov3-dense. Journal of Sensors, 2019:1 - 13, 2019. Hindawi.

[39] X. Zhang, L. Han, Y. Dong, Y. Shi, W. Huang, L. Han, P. González-Moreno, H. Ma, H. Ye, and T Sobeih. A deep learning-based approach for automated yellow rust disease detection from high-resolution hyperspectral uav images. MDPI Open Acess Journal - Remote Sensing in Agriculture and Vegetation, 11:1554, 2019. 
[40] Dongyi Wang, Robert Vinson, Maxwell Holmes, Gary Seibel, Avital Bechar, Shimon Nof, and Yang Tao. Early Detection of Tomato Spotted Wilt Virus by Hyperspectral Imaging and Outlier Removal Auxiliary Classifier Generative Adversarial Nets (OR-AC-GAN). Scientific Reports, 9(1):4377, dec 2018.

[41] Koushik Nagasubramanian, Sarah Jones, Asheesh K. Singh, Soumik Sarkar, Arti Singh, and Baskar Ganapathysubramanian. Plant disease identification using explainable 3d deep learning on hyperspectral images. Plant Methods, 15(1):98, 2019.

[42] Jayme Garcia Arnal Barbedo. Impact of dataset size and variety on the effectiveness of deep learning and transfer learning for plant disease classification. Computers and Electronics in Agriculture, 153:46 - 53, 2018.

[43] P. Goncharov, G. Ososkov, A. Nechaevskiy, A. Uzhinskiy, and I. Nestsiarenia. Disease detection on the plant leaves by deep learning. In Boris Kryzhanovsky, Witali Dunin-Barkowski, Vladimir Redko, and Yury Tiumentsev, editors, Advances in Neural Computation, Machine Learning, and Cognitive Research II, pages 151-159, Cham, 2019. Springer International Publishing.

[44] Martín Abadi, Ashish Agarwal, Paul Barham, Eugene Brevdo, Zhifeng Chen, Craig Citro, Greg S. Corrado, Andy Davis, Jeffrey Dean, Matthieu Devin, Sanjay Ghemawat, Ian Goodfellow, Andrew Harp, Geoffrey Irving, Michael Isard, Yangqing Jia, Rafal Jozefowicz, Lukasz Kaiser, Manjunath Kudlur, Josh Levenberg, Dan Mané, Rajat Monga, Sherry Moore, Derek Murray, Chris Olah, Mike Schuster, Jonathon Shlens, Benoit Steiner, Ilya Sutskever, Kunal Talwar, Paul Tucker, Vincent Vanhoucke, Vijay Vasudevan, Fernanda Viégas, Oriol Vinyals, Pete Warden, Martin Wattenberg, Martin Wicke, Yuan Yu, and Xiaoqiang Zheng. TensorFlow: Large-scale machine learning on heterogeneous systems, 2015. Software available from tensorflow.org.

[45] François Chollet et al. Keras. https://keras.io, 2015.

[46] Olga Russakovsky, Jia Deng, Hao Su, Jonathan Krause, Sanjeev Satheesh, Sean Ma, Zhiheng Huang, Andrej Karpathy, Aditya Khosla, Michael S. Bernstein, Alexander C. Berg, and Fei-Fei Li. Imagenet large scale visual recognition challenge. CoRR, abs/1409.0575, 2014.

[47] H. Charles J. Godfray, Daniel Mason-D'Croz, and Sherman Robinson. Food system consequences of a fungal disease epidemic in a major crop. Philosophical transactions of the Royal Society of London. Series B, Biological sciences, 371(1709):20150467, Dec 2016.

[48] Shanwen Zhang, Subing Zhang, Chuanlei Zhang, Xianfeng Wang, and Yun Shi. Cucumber leaf disease identification with global pooling dilated convolutional neural network. Computers and Electronics in Agriculture, 162:422 - 430, 2019.

[49] Md Mehedi Hasan, Joshua P. Chopin, Hamid Laga, and Stanley J. Miklavcic. Detection and analysis of wheat spikes using convolutional neural networks. Plant Methods, 15, Mar 2019.

[50] Parul Sharma, Yash Paul Singh Berwal, and Wiqas Ghai. Performance analysis of deep learning cnn models for disease detection in plants using image segmentation. Information Processing in Agriculture, 2019.

[51] Qiaokang Liang, Shao Xiang, Yucheng Hu, Gianmarc Coppola, Dan Zhang, and Wei Sun. Pd2se-net: Computer-assisted plant disease diagnosis and severity estimation network. Computers and Electronics in Agriculture, 157:518 - 529, 2019. 
[52] S. Huang, W. Liu, F. Qi, and K. Yang. Development and validation of a deep learning algorithm for the recognition of plant disease. In 2019 IEEE 21st International Conference on High Performance Computing and Communications; IEEE 17th International Conference on Smart City; IEEE 5th International Conference on Data Science and Systems (HPCC/SmartCity/DSS), pages 1951-1957, 2019.

[53] Artzai Picon, Maximiliam Seitz, Aitor Alvarez-Gila, Patrick Mohnke, Amaia Ortiz-Barredo, and Jone Echazarra. Crop conditional convolutional neural networks for massive multi-crop plant disease classification over cell phone acquired images taken on real field conditions. Computers and Electronics in Agriculture, 167:105093, 2019.

[54] Tyr Wiesner-Hanks, Harvey Wu, Ethan Stewart, Chad DeChant, Nicholas Kaczmar, Hod Lipson, Michael A. Gore, and Rebecca J. Nelson. Millimeter-level plant disease detection from aerial photographs via deep learning and crowdsourced data. Frontiers in Plant Science, 10:1550, 2019.

[55] Shanwen Zhang, Wenzhun Huang, and Chuanlei Zhang. Three-channel convolutional neural networks for vegetable leaf disease recognition. Cognitive Systems Research, 53:31 - 41, 2019. Advanced Intelligent Computing.

[56] Wan-jie Liang, Hong Zhang, Gu-feng Zhang, and Hong-xin Cao. Rice Blast Disease Recognition Using a Deep Convolutional Neural Network. Scientific Reports, 9(1):2869, dec 2019.

[57] S. S. Hari, M. Sivakumar, P. Renuga, S. karthikeyan, and S. Suriya. Detection of plant disease by leaf image using convolutional neural network. In 2019 International Conference on Vision Towards Emerging Trends in Communication and Networking (ViTECoN), pages 1-5, March 2019.

[58] Z. Lin, S. Mu, F. Huang, K. A. Mateen, M. Wang, W. Gao, and J. Jia. A unified matrix-based convolutional neural network for fine-grained image classification of wheat leaf diseases. IEEE Access, 7:11570-11590, 2019.

[59] M. Brahimi, S. Mahmoudi, K. Boukhalfa, and A. Moussaoui. Deep interpretable architecture for plant diseases classification. In 2019 Signal Processing: Algorithms, Architectures, Arrangements, and Applications (SPA), pages 111-116, 2019.

[60] Jayme Garcia Arnal Barbedo. Plant disease identification from individual lesions and spots using deep learning. Biosystems Engineering, 180:96 - 107, 2019.

[61] Alwaseela Abdalla, Haiyan Cen, Liang Wan, Reem Rashid, Haiyong Weng, Weijun Zhou, and Yong He. Fine-tuning convolutional neural network with transfer learning for semantic segmentation of ground-level oilseed rape images in a field with high weed pressure. Computers and Electronics in Agriculture, 167:105091, 2019.

[62] U. P. Singh, S. S. Chouhan, S. Jain, and S. Jain. Multilayer convolution neural network for the classification of mango leaves infected by anthracnose disease. IEEE Access, 7:43721-43729, 2019.

[63] Yin Long and Changhua Liu. Research on deep learning method of crop disease identification. In Proceedings of the International Conference on Artificial Intelligence, Information Processing and Cloud Computing, AIIPCC '19, pages 1-6, New York, NY, USA, 2019. Association for Computing Machinery. 
[64] Michael Gomez Selvaraj, Alejandro Vergara, Henry Ruiz, Nancy Safari, Sivalingam Elayabalan, Walter Ocimati, and Guy Blomme. Ai-powered banana diseases and pest detection. Plant Methods, 15(1):92, 2019.

[65] Kamal KC, Zhendong Yin, Mingyang Wu, and Zhilu Wu. Depthwise separable convolution architectures for plant disease classification. Computers and Electronics in Agriculture, 165:104948, 2019.

[66] Madallah Alruwaili, Saad Alanazi, Sameh Abd El-Ghany, and Abdulaziz Shehab. An efficient deep learning model for olive diseases detection. International Journal of Advanced Computer Science and Applications, 10(8), 2019.

[67] Florian Rancon, Lionel Bombrun, Barna Keresztes, and Christian Germain. Comparison of sift encoded and deep learning features for the classification and detection of esca disease in bordeaux vineyards. Remote Sensing, 11(1), 2018.

[68] Clément Douarre, Carlos F. Crispim-Junior, Anthony Gelibert, Laure Tougne, and David Rousseau. Novel data augmentation strategies to boost supervised segmentation of plant disease. Computers and Electronics in Agriculture, 165:104967, 2019.

[69] K. R. Aravind, P. Raja, R. Aniirudh, K. V. Mukesh, R. Ashiwin, and G. Vikas. Grape crop disease classification using transfer learning approach. In Durai Pandian, Xavier Fernando, Zubair Baig, and Fuqian Shi, editors, Proceedings of the International Conference on ISMAC in Computational Vision and Bio-Engineering 2018 (ISMAC-CVB), pages 1623-1633, Cham, 2019. Springer International Publishing.

[70] Aditya Khamparia, Gurinder Saini, Deepak Gupta, Ashish Khanna, Shrasti Tiwari, and Victor Hugo C. de Albuquerque. Seasonal crops disease prediction and classification using deep convolutional encoder network. Circuits, Systems, and Signal Processing, Jan 2019.

[71] Yosuke Toda and Fumio Okura. How Convolutional Neural Networks Diagnose Plant Disease. Plant Phenomics, 2019:1-14, mar 2019.

[72] Muammer Türkoglu and Davut Hanbay. Plant disease and pest detection using deep learning-based features. TURKISH JOURNAL OF ELECTRICAL ENGINEERING \& COMPUTER SCIENCES, 27(3):1636-1651, may 2019.

[73] M. R. Howlader, U. Habiba, R. H. Faisal, and M. M. Rahman. Automatic recognition of guava leaf diseases using deep convolution neural network. In 2019 International Conference on Electrical, Computer and Communication Engineering (ECCE), pages 1-5, Feb 2019.

[74] P. Jiang, Y. Chen, B. Liu, D. He, and C. Liang. Real-time detection of apple leaf diseases using deep learning approach based on improved convolutional neural networks. IEEE Access, 7:59069-59080, 2019.

[75] Ke Lin, Liang Gong, Yixiang Huang, Chengliang Liu, and Junsong Pan. Deep learning-based segmentation and quantification of cucumber powdery mildew using convolutional neural network. Frontiers in Plant Science, 10:155, 2019.

[76] Federico Murcia Labaña, Alberto Ruiz, and Francisco García-Sánchez. Pestdetect: Pest recognition using convolutional neural network. In Rafael Valencia-García, Gema Alcaraz-Mármol, Javier del Cioppo-Morstadt, Néstor Vera-Lucio, and 
Martha Bucaram-Leverone, editors, ICT for Agriculture and Environment, pages 99-108, Cham, 2019. Springer International Publishing.

[77] M. Arsenovic, M. Karanovic, S. Sladojevic, A. Anderla, and D. Stefanovic. Solving current limitations of deep learning based approaches for plant disease detection. MDPI Open Acess Journal - Symmetry, 11(7)(939), 2019.

[78] Solemane Coulibaly, Bernard Kamsu-Foguem, Dantouma Kamissoko, and Daouda Traore. Deep neural networks with transfer learning in millet crop images. Computers in Industry, 108:115 - 120, 2019.

[79] Gerrit Polder, Pieter M. Blok, Hendrik A. C. de Villiers, Jan M. van der Wolf, and Jan Kamp. Potato virus y detection in seed potatoes using deep learning on hyperspectral images. Frontiers in Plant Science, 10:209, 2019.

[80] Gensheng Hu, Xiaowei Yang, Yan Zhang, and Mingzhu Wan. Identification of tea leaf diseases by using an improved deep convolutional neural network. Sustainable Computing: Informatics and Systems, 24:100353, 2019.

[81] Hee-Jin Yu and Chang-Hwan Son. Apple leaf disease identification through region-of-interest-aware deep convolutional neural network. ArXiv, abs/1903.10356, 2019.

[82] Amanda Ramcharan, Peter McCloskey, Kelsee Baranowski, Neema Mbilinyi, Latifa Mrisho, Mathias Ndalahwa, James Legg, and David P. Hughes. A mobile-based deep learning model for cassava disease diagnosis. Frontiers in Plant Science, 10:272, 2019.

[83] Geetharamani G. and Arun Pandian J. Identification of plant leaf diseases using a nine-layer deep convolutional neural network. Computers \& Electrical Engineering, 76:323 - 338, 2019.

[84] Jie Hang, Dexiang Zhang, Peng Chen, Jun Zhang, and Bing Wang. Classification of plant leaf diseases based on improved convolutional neural network. Sensors (Basel, Switzerland), 19(19):4161, Sep 2019.

[85] Malusi Sibiya and Mbuyu Sumbwanyambe. A computational procedure for the recognition and classification of maize leaf diseases out of healthy leaves using convolutional neural networks. AgriEngineering, 1(1):119-131, 2019.

[86] Qimei Wang, Feng Qi, Minghe Sun, Jianhua Qu, and Jie Xue. Identification of tomato disease types and detection of infected areas based on deep convolutional neural networks and object detection techniques. Computational Intelligence and Neuroscience, 2019(9142753):15, 2019.

[87] Mehmet Metin Ozguven and Kemal Adem. Automatic detection and classification of leaf spot disease in sugar beet using deep learning algorithms. Physica A: Statistical Mechanics and its Applications, 535:122537, 2019.

[88] Jing Chen, Qi Liu, and Lingwang Gao. Visual tea leaf disease recognition using a convolutional neural network model. Symmetry, 11(3), 2019.

[89] Harvey Wu, Tyr Wiesner-Hanks, Ethan L. Stewart, Chad DeChant, Nicholas Kaczmar, Michael A. Gore, Rebecca J. Nelson, and Hod Lipson. Autonomous detection of plant disease symptoms directly from aerial imagery. The Plant Phenome Journal, 2(1):190006, 2019. 
[90] Belal A. M. Ashqar and Samy S. Abu-Naser. Image-based tomato leaves diseases detection using deep learning. International Journal of Academic Engineering Research (IJAER), 2(1T2):10-16, 2019.

[91] M. Zhang, S. Liu, F. Yang, and J. Liu. Classification of canker on small datasets using improved deep convolutional generative adversarial networks. IEEE Access, 7:49680-49690, 2019.

[92] Shuli Xing, Marely Lee, and Keun-Kwang Lee. Citrus pests and diseases recognition model using weakly dense connected convolution network. Sensors (Basel, Switzerland), 19(14):3195, Jul 2019.

[93] S. André Abade, Ana Paula G. S. de Almeida., and F. B. Vidal. Plant diseases recognition from digital images using multichannel convolutional neural networks. In Proceedings of the 14th International Joint Conference on Computer Vision, Imaging and Computer Graphics Theory and Applications - Volume 5: VISAPP,, pages 450-458. INSTICC, SciTePress, 2019.

[94] Wang Dawei, Deng Limiao, Ni Jiangong, Gao Jiyue, Zhu Hongfei, and Han Zhongzhi. Recognition pest by image-based transfer learning. Journal of the Science of Food and Agriculture, 99(10):4524-4531, 2019.

[95] Aydin Kaya, Ali Seydi Keceli, Cagatay Catal, Hamdi Yalin Yalic, Huseyin Temucin, and Bedir Tekinerdogan. Analysis of transfer learning for deep neural network based plant classification models. Computers and Electronics in Agriculture, 158:20 29, 2019.

[96] C. Lin, Q. Ding, W. Tu, J. Huang, and J. Liu. Fourier dense network to conduct plant classification using uav-based optical images. IEEE Access, 7:17736-17749, 2019.

[97] E. Suryawati, R. Sustika, R. S. Yuwana, A. Subekti, and H. F. Pardede. Deep structured convolutional neural network for tomato diseases detection. In 2018 International Conference on Advanced Computer Science and Information Systems (ICACSIS), pages 385-390, Oct 2018.

[98] R. Gandhi, S. Nimbalkar, N. Yelamanchili, and S. Ponkshe. Plant disease detection using cnns and gans as an augmentative approach. In 2018 IEEE International Conference on Innovative Research and Development (ICIRD), pages 1-5, May 2018.

[99] Edna Chebet Too, Li Yujian, Sam Njuki, and Liu Yingchun. A comparative study of fine-tuning deep learning models for plant disease identification. Computers and Electronics in Agriculture, 161:272 - 279, 2018. BigData and DSS in Agriculture.

[100] R. G. de Luna, E. P. Dadios, and A. A. Bandala. Automated image capturing system for deep learning-based tomato plant leaf disease detection and recognition. In TENCON 2018 - 2018 IEEE Region 10 Conference, pages 1414-1419, Oct 2018.

[101] Mohammed Brahimi, Marko Arsenovic, Sohaib Laraba, Srdjan Sladojevic, Kamel Boukhalfa, and Abdelouhab Moussaoui. Deep Learning for Plant Diseases: Detection and Saliency Map Visualisation, pages 93-117. Springer International Publishing, Cham, 2018.

[102] M. Sardogan, A. Tuncer, and Y. Ozen. Plant leaf disease detection and classification based on cnn with lvq algorithm. In 2018 3rd International Conference on Computer Science and Engineering (UBMK), pages 382-385, Sep. 2018. 
[103] Konstantinos P. Ferentinos. Deep learning models for plant disease detection and diagnosis. Computers and Electronics in Agriculture, 145:311 - 318, 2018

[104] J. Li, J. Jia, and D. Xu. Unsupervised representation learning of image-based plant disease with deep convolutional generative adversarial networks. In 2018 37th Chinese Control Conference (CCC), pages 9159-9163, July 2018.

[105] A. L. P. d. Ocampo and E. P. Dadios. Mobile platform implementation of lightweight neural network model for plant disease detection and recognition. In 2018 IEEE 10th International Conference on Humanoid, Nanotechnology, Information Technology, Communication and Control, Environment and Management (HNICEM), pages 1-4, Nov 2018.

[106] H. Q. Cap, K. Suwa, E. Fujita, S. Kagiwada, H. Uga, and H. Iyatomi. A deep learning approach for on-site plant leaf detection. In 2018 IEEE 14th International Colloquium on Signal Processing Its Applications (CSPA), pages 118-122, March 2018.

[107] H. F. Pardede, E. Suryawati, R. Sustika, and V. Zilvan. Unsupervised convolutional autoencoder-based feature learning for automatic detection of plant diseases. In 2018 International Conference on Computer, Control, Informatics and its Applications (IC3INA), pages 158-162, Nov 2018.

[108] Keke Zhang, Qiufeng Wu, Anwang Liu, and Xiangyan Meng. Can deep learning identify tomato leaf disease? Adv. in MM, 2018:6710865:1-6710865:10, 2018.

[109] Jingxian Wang, Lei Chen, Jian Zhang, Yuan Yuan, Miao Li, and WeiHui Zeng. Cnn transfer learning for automatic image-based classification of crop disease. In Yongtian Wang, Zhiguo Jiang, and Yuxin Peng, editors, Image and Graphics Technologies and Applications, pages 319-329, Singapore, 2018. Springer Singapore.

[110] K. K. Singh. An artificial intelligence and cloud based collaborative platform for plant disease identification, tracking and forecasting for farmers. In 2018 IEEE International Conference on Cloud Computing in Emerging Markets (CCEM), pages 49-56, Nov 2018.

[111] X. Zhang, Y. Qiao, F. Meng, C. Fan, and M. Zhang. Identification of maize leaf diseases using improved deep convolutional neural networks. IEEE Access, 6:30370-30377, 2018.

[112] K. Kobayashi, J. Tsuji, and M. Noto. Evaluation of data augmentation for image-based plant-disease detection. In 2018 IEEE International Conference on Systems, Man, and Cybernetics (SMC), pages 2206-2211, Oct 2018.

[113] Jayme G.A. Barbedo. Factors influencing the use of deep learning for plant disease recognition. Biosystems Engineering, 172:84 - 91, 2018

[114] Keunho Park, Young ki Hong, Gook hwan Kim, and Joonwhoan Lee. Classification of apple leaf conditions in hyper-spectral images for diagnosis of marssonina blotch using mrmr and deep neural network. Computers and Electronics in Agriculture, $148: 179-187,2018$

[115] Alvaro F. Fuentes, Sook Yoon, Jaesu Lee, and Dong Sun Park. High-performance deep neural network-based tomato plant diseases and pests diagnosis system with refinement filter bank. Frontiers in Plant Science, 9:1162, 2018. 
[116] Yuan Yuan, Sisi Fang, and Lei Chen. Crop disease image classification based on transfer learning with denns. In Jian-Huang Lai, Cheng-Lin Liu, Xilin Chen, Jie Zhou, Tieniu Tan, Nanning Zheng, and Hongbin Zha, editors, Pattern Recognition and Computer Vision, pages 457-468, Cham, 2018. Springer International Publishing.

[117] Artzai Picon, Aitor Alvarez-Gila, Maximiliam Seitz, Amaia Ortiz-Barredo, Jone Echazarra, and Alexander Johannes. Deep convolutional neural networks for mobile capture device-based crop disease classification in the wild. Computers and Electronics in Agriculture, 161:280 - 290, 2018. BigData and DSS in Agriculture.

[118] P. Tm, A. Pranathi, K. SaiAshritha, N. B. Chittaragi, and S. G. Koolagudi. Tomato leaf disease detection using convolutional neural networks. In 2018 Eleventh International Conference on Contemporary Computing (IC3), pages 1-5, Aug 2018.

[119] Guoliang Yang, Nan Xu, and Zhiyang Hong. Identification of navel orange lesions by nolinear deep learning algorithm. Engenharia AgrÃcola, 38:783 - 796, 092018.

[120] Shichao Jin, Yanjun Su, Shang Gao, Fangfang Wu, Tianyu Hu, Jin Liu, Wenkai Li, Dingchang Wang, Shaojiang Chen, Yuanxi Jiang, Shuxin Pang, and Qinghua Guo. Deep learning: Individual maize segmentation from terrestrial lidar data using faster r-cnn and regional growth algorithms. Frontiers in Plant Science, 9:866, 2018.

[121] Serawork Wallelign, Mihai Polceanu, and Cédric Buche. Soybean Plant Disease Identification Using Convolutional Neural Network. In FLAIRS-31, pages 146-151, Melbourne, United States, May 2018.

[122] L. Minh Dang, Syed [Ibrahim Hassan], Im Suhyeon, Arun kumar Sangaiah, Irfan Mehmood, Seungmin Rho, Sanghyun Seo, and Hyeonjoon Moon. Uav based wilt detection system via convolutional neural networks. Sustainable Computing: Informatics and Systems, 2018.

[123] L. Ren, M. Hu, Y. Fang, X. Du, and H. Feng. Recognition of common pests in agriculture and forestry based on convolutional neural networks. In 2018 Chinese Automation Congress (CAC), pages 2985-2989, Nov 2018.

[124] Muhammad Attique Khan, Tallha Akram, Muhammad Sharif, Muhammad Awais, Kashif Javed, Hashim Ali, and Tanzila Saba. Ccdf: Automatic system for segmentation and recognition of fruit crops diseases based on correlation coefficient and deep cnn features. Computers and Electronics in Agriculture, 155:220 - 236, 2018.

[125] Ahmad Arib Alfarisy, Quan Chen, and Minyi Guo. Deep learning based classification for paddy pests \&\#38; diseases recognition. In Proceedings of 2018 International Conference on Mathematics and Artificial Intelligence, ICMAI '18, pages 21-25, New York, NY, USA, 2018. ACM.

[126] Hadrian Paulo M. Lim and Maria Regina Justina E. Estuar. Microscopic fusarium detection and verification with convolutional neural networks. In Proceedings of the 2018 International Conference on Machine Learning Technologies, ICMLT '18, pages 48-52, New York, NY, USA, 2018. ACM. 
[127] Juncheng Ma, Keming Du, Feixiang Zheng, Lingxian Zhang, Zhihong Gong, and Zhongfu Sun. A recognition method for cucumber diseases using leaf symptom images based on deep convolutional neural network. Computers and Electronics in Agriculture, 154:18 - 24, 2018.

[128] Ronnel R. Atole and Daechul Park. A multiclass deep convolutional neural network classifier for detection of common rice plant anomalies. International Journal of Advanced Computer Science and Applications, 9(1), 2018.

[129] Chowdhury Rafeed Rahman, Preetom Saha Arko, Mohammed Eunus Ali, Mohammad Ashik Iqbal Khan, Abu Wasif, Md. Rafsan Jani, and Md. Shahjahan Kabir. Identification and recognition of rice diseases and pests using deep convolutional neural networks. CoRR, abs/1812.01043, 2018.

[130] Dor Oppenheim, Guy Shani, Orly Erlich, and Leah Tsror. Using deep learning for image-based potato tuber disease detection. Phytopathology, 109(6):1083-1087, 2019. PMID: 30543489.

[131] Aravind Krishnaswamy Rangarajan, Raja Purushothaman, and Aniirudh Ramesh. Tomato crop disease classification using pre-trained deep learning algorithm. Procedia Computer Science, 133:1040 - 1047, 2018. International Conference on Robotics and Smart Manufacturing (RoSMa2018).

[132] Sheng-Hung Lee, Chia-Chang Wu, and Shih-Fang Chen. Development of Image Recognition and Classification Algorithm for Tea Leaf Diseases Using Convolutional Neural Network. In 2018 Detroit, Michigan July 29 - August 1, 2018, page 1, St. Joseph, MI, 2018. American Society of Agricultural and Biological Engineers.

[133] Yu Li, Meiyu Qian, Pengfeng Liu, Qian Cai, Xiaoying Li, Junwen Guo, Huan Yan, Fengyuan Yu, Kun Yuan, Juan Yu, Luman Qin, Hongxin Liu, Wan Wu, Peiyun Xiao, and Ziwei Zhou. The recognition of rice images by uav based on capsule network. Cluster Computing, Mar 2018.

[134] Zhen Wang and Shanwen Zhang. Segmentation of corn leaf disease based on fully convolution neural network. In Francis-Press - Open Access Journals and Proceedings, pages 9-18, 2018.

[135] Mohamed Kerkech, Adel Hafiane, and Raphael Canals. Deep leaning approach with colorimetric spaces and vegetation indices for vine diseases detection in uav images. Computers and Electronics in Agriculture, 155:237 - 243, 2018.

[136] Erika Fujita, Hiroyuki Uga, Satoshi Kagiwada, and Hitoshi Iyatomi. A practical plant diagnosis system for field leaf images and feature visualization. In International Journal of Engineering \& Technology, pages 49-54, 2018.

[137] H. Durmus, E. O. Günes, and M. Kırcı. Disease detection on the leaves of the tomato plants by using deep learning. In 2017 6th International Conference on Agro-Geoinformatics, pages 1-5, Aug 2017.

[138] Yang Lu, Shujuan Yi, Nianyin Zeng, Yurong Liu, and Yong Zhang. Identification of rice diseases using deep convolutional neural networks. Neurocomputing, 267:378 - 384, 2017.

[139] Guan Wang, Yu Sun, and Jianxin Wang. Automatic Image-Based Plant Disease Severity Estimation Using Deep Learning. Computational Intelligence and Neuroscience, 2017:1-8, jul 2017. 
[140] Alvaro Fuentes, Sook Yoon, Sang Cheol Kim, and Dong Sun Park. A robust deep-learning-based detector for real-time tomato plant diseases and pests recognition. Sensors, 17(9), 2017.

[141] Chad DeChant, Tyr Wiesner-Hanks, Siyuan Chen, Ethan L. Stewart, Jason Yosinski, Michael A. Gore, Rebecca J. Nelson, and Hod Lipson. Automated identification of northern leaf blight-infected maize plants from field imagery using deep learning. Phytopathology, 107(11):1426-1432, 2017. PMID: 28653579.

[142] H. Park, J. Eun, and S. Kim. Image-based disease diagnosing and predicting of the crops through the deep learning mechanism. In 2017 International Conference on Information and Communication Technology Convergence (ICTC), pages 129-131, Oct 2017.

[143] Habibollah Agh Atabay. Deep residual learning for tomato plant leaf disease identification. Journal of Theoretical and Applied Information Technology, 95:866, 2017.

[144] Amanda Ramcharan, Kelsee Baranowski, Peter McCloskey, Babuali Ahmed, James Legg, and David P. Hughes. Deep learning for image-based cassava disease detection. Frontiers in Plant Science, 8:1852, 2017.

[145] Z. Peng and C. Cai. An effective segmentation algorithm of apple watercore disease region using fully convolutional neural networks. In 2017 Asia-Pacific Signal and Information Processing Association Annual Summit and Conference (APSIPA ASC), pages 1292-1299, Dec 2017.

[146] Kyosuke Yamamoto, Takashi Togami, and Norio Yamaguchi. Super-resolution of plant disease images for the acceleration of image-based phenotyping and vigor diagnosis in agriculture. Sensors, 17(11), 2017.

[147] Milan Šulc and Jiří Matas. Fine-grained recognition of plants from images. Plant Methods, 13(1):115, dec 2017.

[148] Emanuel Cortes. Plant Disease Classification Using Convolutional Networks and Generative Adverserial Networks. Technical report, Stanford University, 2017.

[149] Yu Sun, Lin Zhu, Guan Wang, and Fang Zhao. Multi-Input Convolutional Neural Network for Flower Grading. Journal of Electrical and Computer Engineering, 2017:1-8, aug 2017.

[150] Jin Gwan Ha, Hyeonjoon Moon, Jin Tae Kwak, Syed Ibrahim Hassan, Minh Dang, O New Lee, and Han Yong Park. Deep convolutional neural network for classifying fusarium wilt of radish from unmanned aerial vehicles. Journal of Applied Remote Sensing, 11(4): 1 - $14-14,2017$.

[151] Jihen Amara, Bassem Bouaziz, and Alsayed Algergawy. A deep learning-based approach for banana leaf diseases classification. In $B T W$, pages 12-20, 2017.

[152] Srdjan Sladojevic, Marko Arsenovic, Andras Anderla, Dubravko Culibrk, and Darko Stefanovic. Deep Neural Networks Based Recognition of Plant Diseases by Leaf Image Classification. Computational Intelligence and Neuroscience, 2016:1-11, jun 2016. 
[153] Wenxue Tan, Chunjiang Zhao, and Huarui Wu. Intelligent alerting for fruit-melon lesion image based on momentum deep learning. Multimedia Tools and Applications, 75(24):16741-16761, Dec 2016.

[154] L. G. Nachtigall, R. M. Araujo, and G. R. Nachtigall. Classification of apple tree disorders using convolutional neural networks. In 2016 IEEE 28th International Conference on Tools with Artificial Intelligence (ICTAI), pages 472-476, Nov 2016.

[155] E. Fujita, Y. Kawasaki, H. Uga, S. Kagiwada, and H. Iyatomi. Basic investigation on a robust and practical plant diagnostic system. In 2016 15th IEEE International Conference on Machine Learning and Applications (ICMLA), pages 989-992, Dec 2016.

[156] Habibollah Agh Atabay. A convolutional neural network with a new architecture applied on leaf classification. IIOAB $J$, 7(5):226-331, 2016.

[157] Yusuke Kawasaki, Hiroyuki Uga, Satoshi Kagiwada, and Hitoshi Iyatomi. Basic study of automated diagnosis of viral plant diseases using convolutional neural networks. In George Bebis, Richard Boyle, Bahram Parvin, Darko Koracin, Ioannis Pavlidis, Rogerio Feris, Tim McGraw, Mark Elendt, Regis Kopper, Eric Ragan, Zhao Ye, and Gunther Weber, editors, Advances in Visual Computing, pages 638-645, Cham, 2015. Springer International Publishing. 